\title{
Experimental Investigation and FE Analysis on Constitutive Relationship of High Strength Aluminum Alloy under Cyclic Loading
}

\author{
Yuanqing Wang and Zhongxing Wang \\ Department of Civil Engineering, Tsinghua University, Beijing 10084, China \\ Correspondence should be addressed to Zhongxing Wang; 1534307298@qq.com
}

Received 13 May 2016; Revised 16 August 2016; Accepted 28 August 2016

Academic Editor: Hiroshi Noguchi

Copyright (C) 2016 Y. Wang and Z. Wang. This is an open access article distributed under the Creative Commons Attribution License, which permits unrestricted use, distribution, and reproduction in any medium, provided the original work is properly cited.

\begin{abstract}
Experiments of 17 high strength aluminum alloy (7A04) specimens were conducted to investigate the constitutive relationship under cyclic loading. The monotonic behavior and hysteretic behavior were focused on and the fracture surface was observed by scanning electron microscope (SEM) to investigate the microfailure modes. Based on Ramberg-Osgood model, stress-strain skeleton curves under cyclic loading were fitted. Parameters of combined hardening model including isotropic hardening and kinematic hardening were calibrated from test data according to Chaboche model. The cyclic tests were simulated in finite element software ABAQUS. The test results show that 7A04 aluminum alloy has obvious nonlinearity and ultra-high strength which is over $600 \mathrm{MPa}$, however, with relatively poor ductility. In the cyclic loading tests, 7A04 aluminum alloy showed cyclic hardening behavior and when the compressive strain was larger than $1 \%$, the stiffness degradation and strength degradation occurred. The simulated curves derived by FE model fitted well with experimental curves which indicates that the parameters of this combined model can be used in accurate calculation of 7A04 high strength aluminum structures under cyclic loading.
\end{abstract}

\section{Introduction}

With the development of aluminum alloy structures, the research on constitutive relationship of aluminum alloy and aluminum alloy members is gradually deepening. Much recent research activity about aluminum alloy has centred on static research including stability behavior research [1-3], research on joints $[4,5]$, research on fatigue crack $[6,7]$, and research on overall aluminum alloy structures [8]. However, the research work of aluminum alloy members or structures under dynamic loading [9] is scant. With the rapid development of metallurgical industry, high strength aluminum alloy (HSAA) starts to be applied as main supporting members in engineering structures. The research on seismic performance of aluminum alloy structures or members will be a big trend. As the premise of the seismic performance analysis, the constitutive relationship of HSAA under cyclic loading is the important basis.

The research on the constitutive relationship of aluminum alloy was focused on its monotonic behavior.
Ramberg-Osgood presented a nonlinear constitutive model of aluminum alloy in 1943 [10]:

$$
\varepsilon=\frac{\sigma}{E}+\left(\frac{\sigma}{f_{0.2}}\right)^{n} .
$$

In 1971, Steinhardt presented a method which can simplify the calculation of " $n$ " in Ramberg-Osgood model and has been applied widely [11], as is shown in

$$
10 n=f_{0.2}(\mathrm{MPa}) .
$$

Mazzolani also presented his constitutive model of aluminum alloy [12], but this model is seldom used.

Chaboche plastic constitutive model [13] is usually applied to describe the constitutive relationship of metal material under cyclic loading. Chaboche model is a combined hardening model including isotropic hardening component and nonlinear kinetic hardening component. However, there is nearly no test of aluminum alloy conducted to calibrate the 


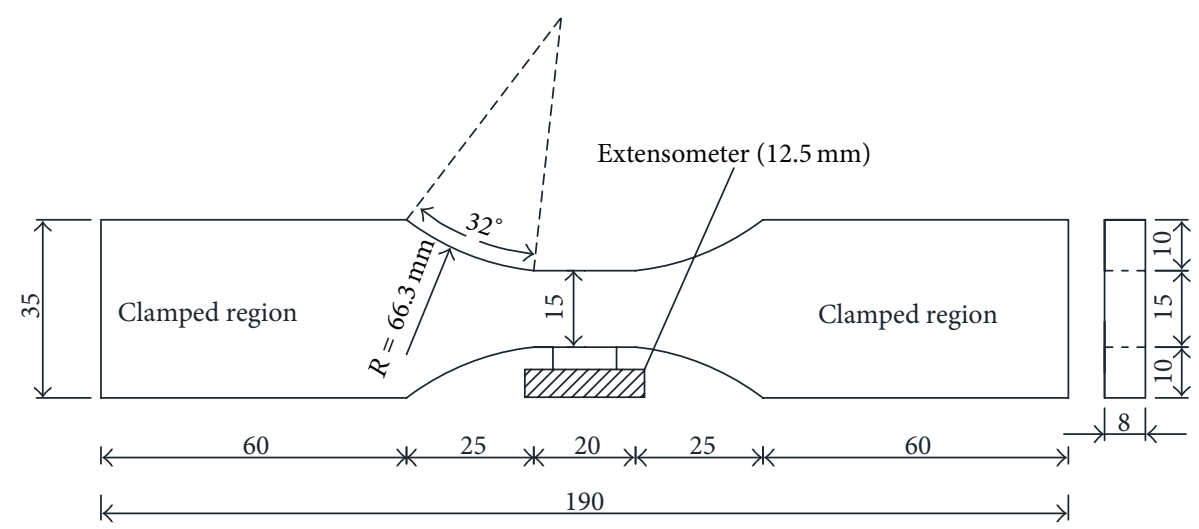

FIGURE 1: Dimension of the specimen.

TABLE 1: Chemical composition (\%) of 7A04 aluminum alloy.

\begin{tabular}{lccccc}
\hline \multirow{2}{*}{ Material } & \multicolumn{5}{c}{ Mass fraction/\% } \\
& $\mathrm{Si}$ & $\mathrm{Fe}$ & $\mathrm{Cu}$ & $\mathrm{Mn}$ & $\mathrm{Zn}$ \\
\hline 7A04 & 0.6 & 0.7 & 0.05 & 1.0 & 0.1 \\
\hline
\end{tabular}

parameters in Chaboche model which limits the research of aluminum alloy structures under cyclic or seismic loading.

7A04 HSAA is Al- $\mathrm{Zn}-\mathrm{Mg}-\mathrm{Cu}$ series aluminum alloy, with nominal yield stress over $500 \mathrm{MPa}$, which has been applied in aerospace field. Recent years, several transmission tower structures and military engineering structures intend to use the 7A04 HSAA as the main structural material. Zhang et al. conducted a research on static constitutive relationship on 7A04 HSAA in 2011 [14]. However, there is no research of 7A04 HSAA on the constitutive relationship under cyclic loading.

In the current paper, 2 monotonic loading tests and 15 cyclic loading tests were conducted. Monotonic behavior and hysteretic behavior of the material were analyzed. SEM was used to observe the crack surface in order to study the microfailure modes of the material. Stress-strain skeleton curves under cyclic loading were fitted based on Ramberg-Osgood model. After calibration of the parameters in Chaboche model, FE software ABAQUS was used to simulate the corresponding tests. The purpose of this paper is to supply a basis for calculation of 7A04 HSAA structures under cyclic loading.

\section{Experimental Investigation}

2.1. Test Specimens. Plates are usually used in structure engineering; therefore, 17 specimens were cut from HSAA plates. The dimension of the specimen is shown in Figure 1. The chemical composition of 7A04 HSAA is shown in Table 1.

2.2. Test Set-Up. Monotonic loading and cyclic loading were carried out on INSTRON 8801 testing machine, as is shown in Figure 2. The strain of specimens was measured by extensometer connected with the testing machine with gauge length of $12.5 \mathrm{~mm}$ and measuring range of $\pm 35 \%$.

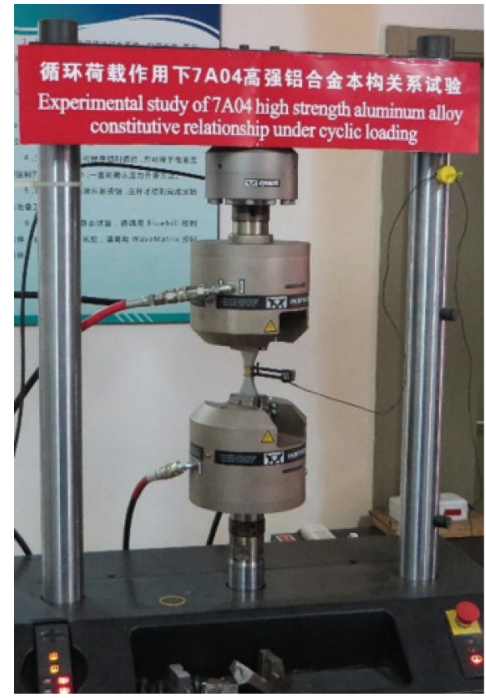

Figure 2: Test set-up.

The layout of the extensometer is shown in Figure 1. Strain controlled loading was adopted in the test. Stress, strain, and displacement were collected by computer in real time, and the acquisition frequency is $20 \mathrm{~Hz}$.

Specimens M1 and M2 were tested under monotonic loading. Specimens H1 H15 were tested under different kinds of cyclic loading to investigate the hysteretic behavior and constitutive characteristics. After the cyclic loading, the specimens were loaded until tension failure. All of the cyclic loading system is shown in Figure 3.

\section{Test Results and Analysis}

3.1. Test Results. Test results of monotonic loading and cyclic loading are summarized in Tables 2 and 3. Specimen H1 failed in the 6th loading cycle, not reaching the ultimate strength.

3.2. Monotonic Behavior. Stress-strain curves of monotonic loading are shown in Figure 4. It can be found from Figure 4 and Table 2 that the nominal yield strength of 7A04 HSAA is about $540 \mathrm{MPa}$, and the ultimate strength is about $600 \mathrm{MPa}$. 


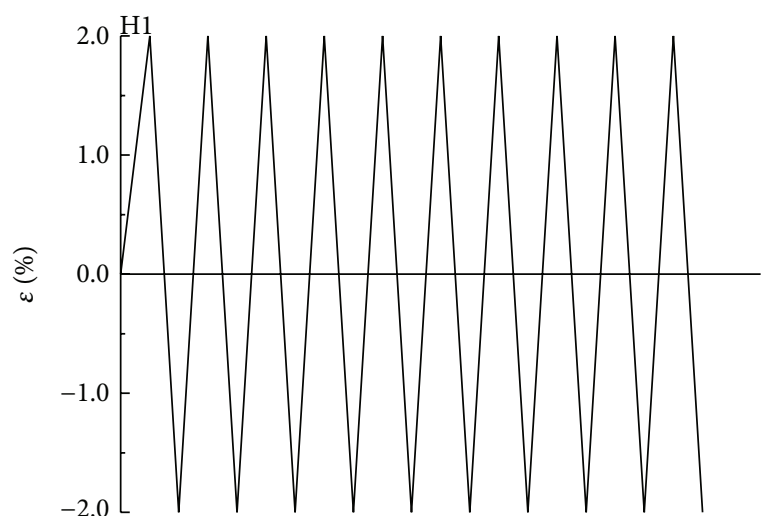

(a) $\mathrm{H} 1$

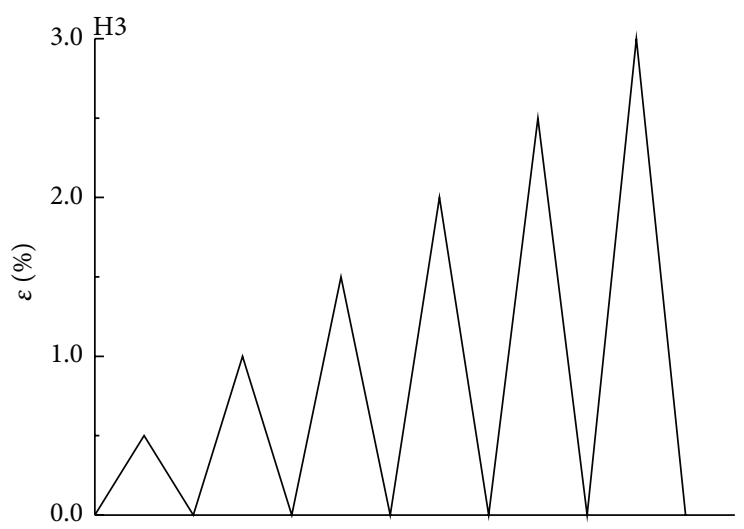

(c) $\mathrm{H} 3$

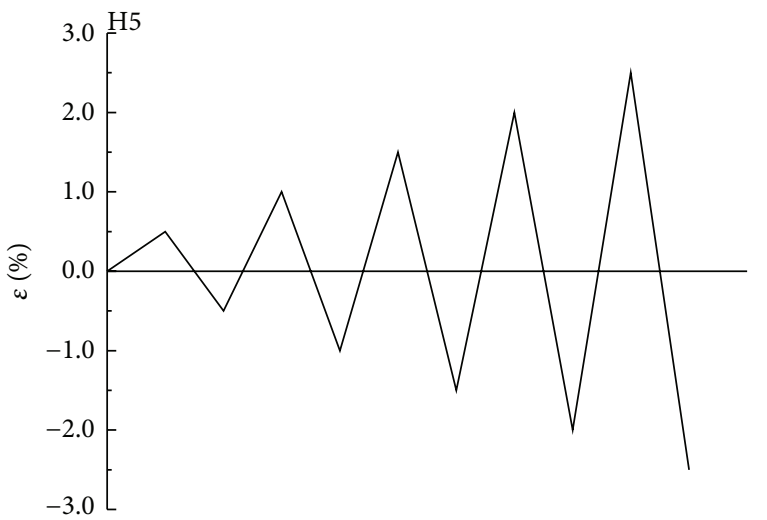

(e) $\mathrm{H} 5$

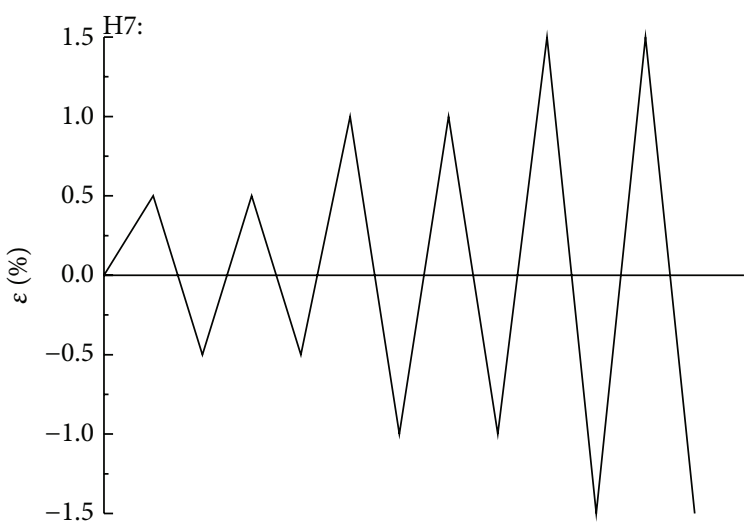

(g) H7

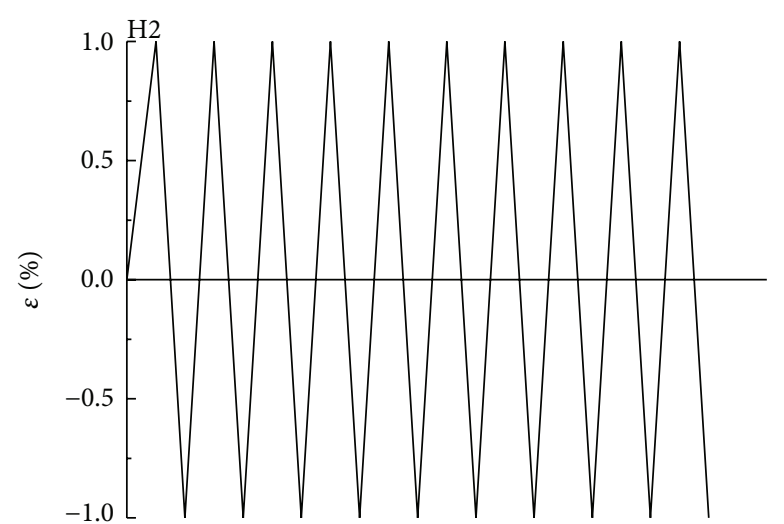

(b) $\mathrm{H} 2$

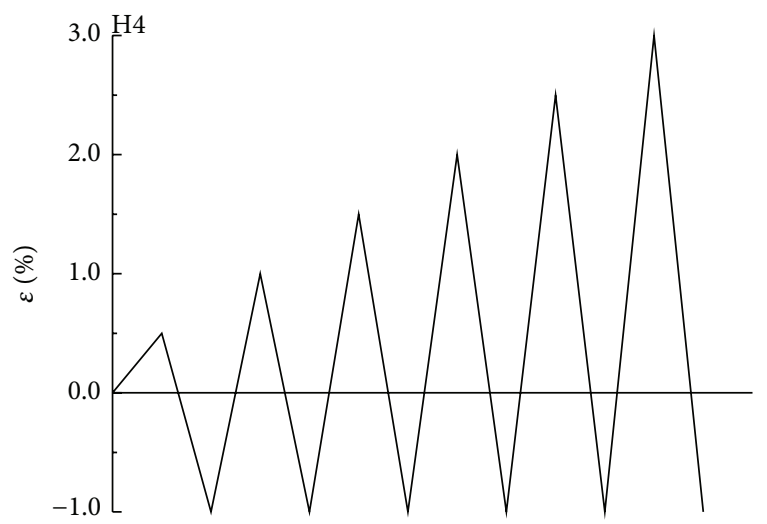

(d) $\mathrm{H} 4$

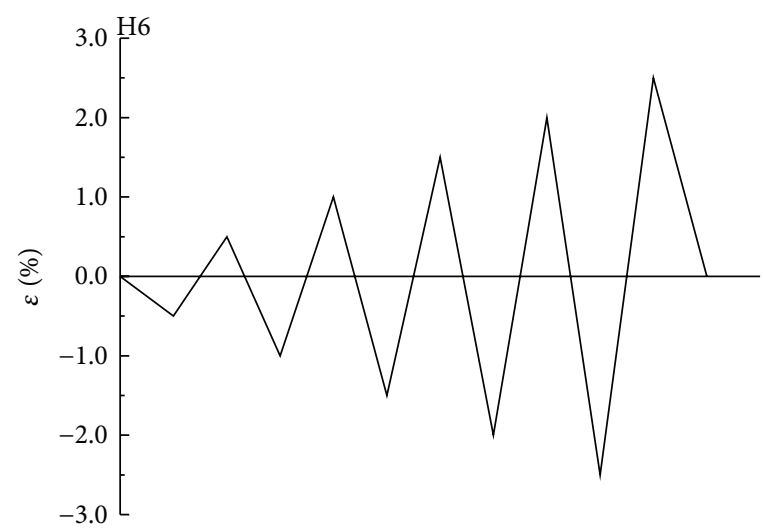

(f) $\mathrm{H} 6$

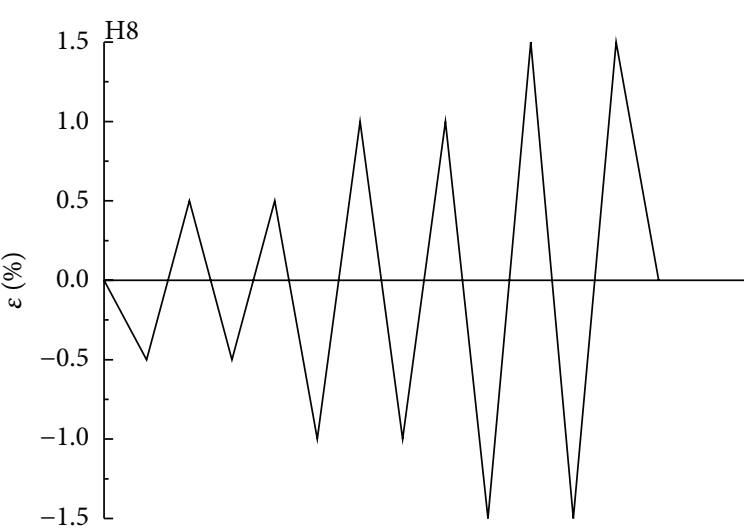

(h) $\mathrm{H} 8$

FIgUre 3: Continued. 


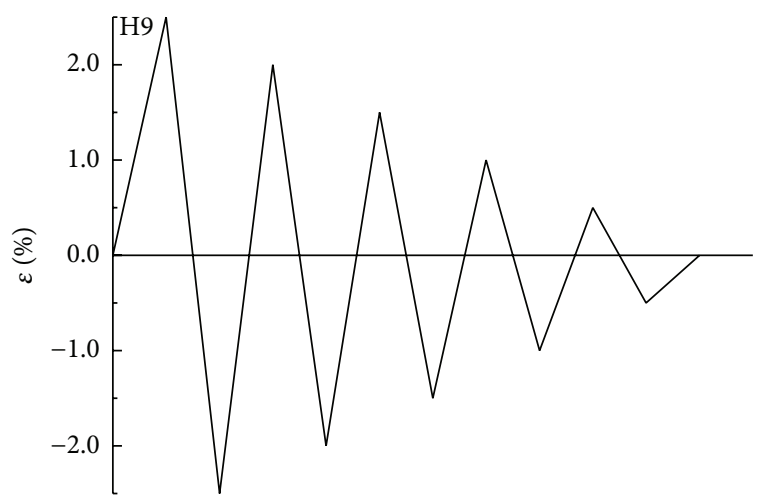

(i) $\mathrm{H} 9$

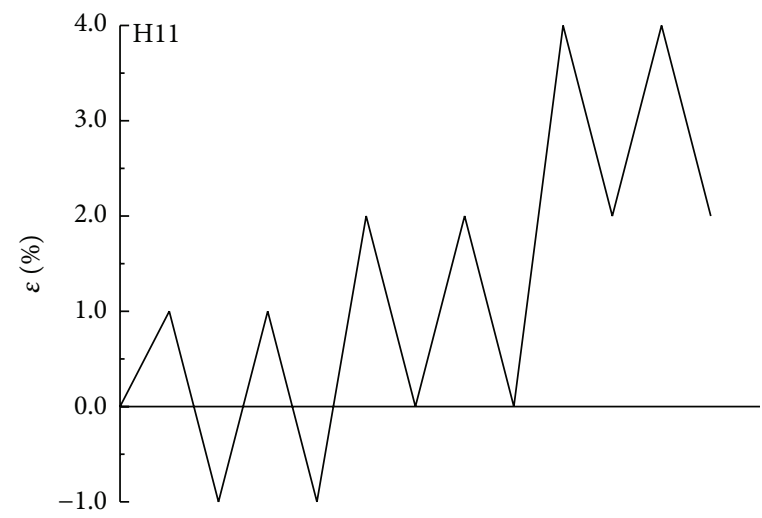

(k) H11

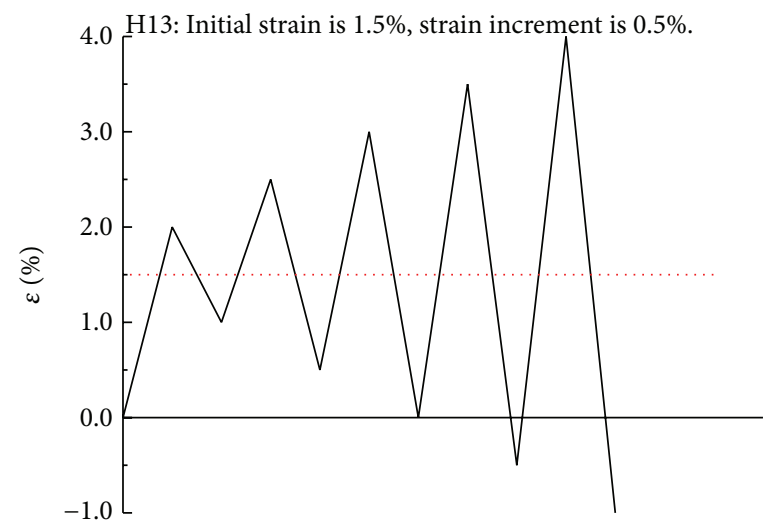

(m) $\mathrm{H} 13$

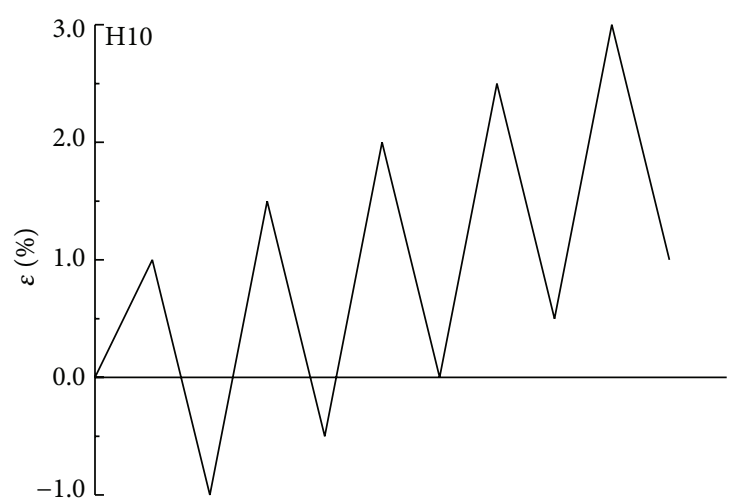

(j) $\mathrm{H} 10$

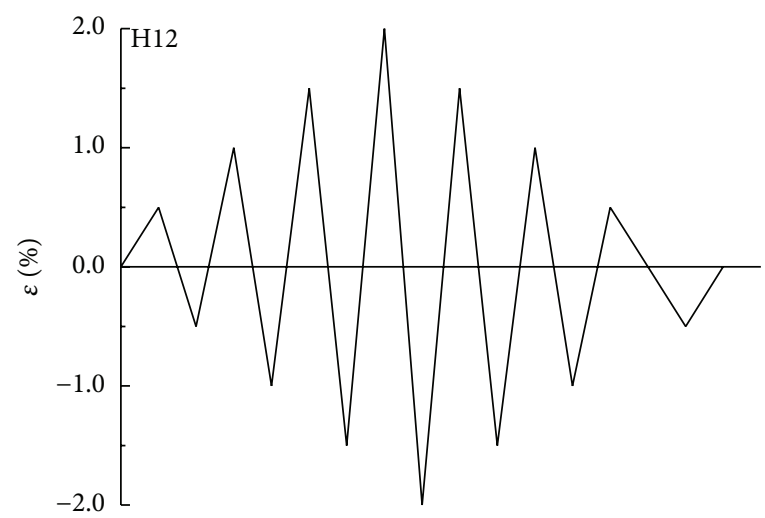

(1) $\mathrm{H} 12$

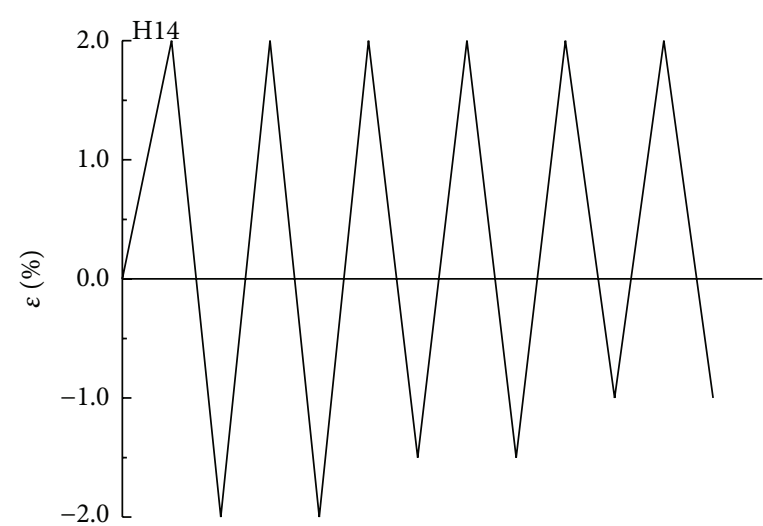

(n) $\mathrm{H} 14$

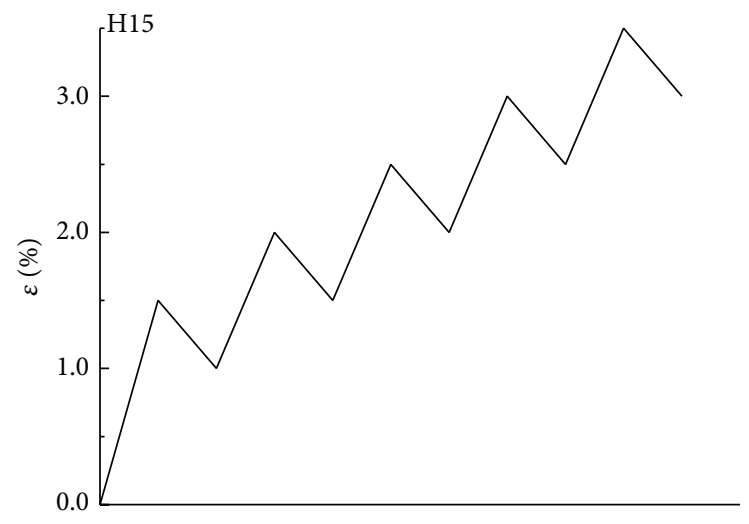

(o) H15

Figure 3: Cyclic loading system. 
TABLE 2: Test results of monotonic loading.

\begin{tabular}{lcccccc}
\hline Specimen & $f_{0.2} / \mathrm{MPa}$ & $f_{u} / \mathrm{MPa}$ & $f_{u 2} / \mathrm{MPa}$ & $\varepsilon_{1} / \%$ & $\varepsilon_{u} / \%$ & $\varepsilon_{2} \%$ \\
\hline $\mathrm{M} 1$ & 552.95 & 605.04 & 593.43 & 0.92 & 8.77 & 11.71 \\
$\mathrm{M} 2$ & 537.36 & 593.76 & 589.84 & 0.89 & 8.01 & 9.98 \\
\hline
\end{tabular}

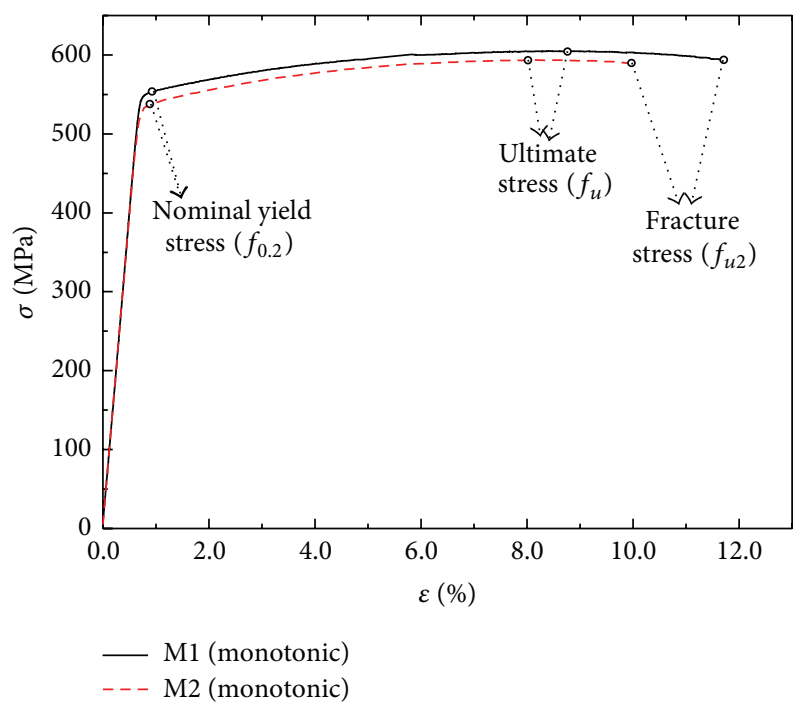

FIGURE 4: Stress-strain curves of monotonic loading.

The strength of 7A04 HSAA is close to Q460 high strength steel. There are no obvious yield plateau and descending stage in the stress-strain curve. The fracture strength is decreased by $1.3 \%$ compared with the ultimate strength. The failure process is very sudden without visible necking phenomenon. The ductility is relatively poor with $10 \%$ ultimate strain.

Figure 5 is the comparison between monotonic curves and cyclic loading curves. Because of Bauschinger effect, cyclic hardening effect, and cyclic softening effect, there is difference between the monotonic curve and cyclic loading curves. The strength in strain-hardening ranges of cyclic loading curves is higher than that of monotonic curves. However, because of plastic damage, the ultimate strengths of monotonic curves and cyclic loading curves are nearly the same. The plastic damage has been marked in Figure 5 which makes a sudden drop of the curve when there is a relatively large stress. Plastic damage phenomenon is found in the loading process of $\mathrm{H} 1, \mathrm{H} 3 \sim \mathrm{H} 6, \mathrm{H} 9 \sim \mathrm{H} 10$, and $\mathrm{H} 12 \sim \mathrm{H} 15$.

3.3. Hysteretic Behavior. To study the hysteretic behavior of material is to study the constitutive response of the material under cyclic loading. The stress-strain curves of H1 H15 under cyclic loading are shown in Figure 6; the hysteretic behavior of 7A04 HSAA is shown as follows:

(1) By constant-amplitude cyclic loading, the stress of specimens $\mathrm{H} 1$ and $\mathrm{H} 2$ increases at the same strain with the increase of hysteretic cycles. The material shows typical cyclic hardening effect.

(2) For most specimens, the stiffness degradation and strength degradation occurred after $1 \%$ compressive

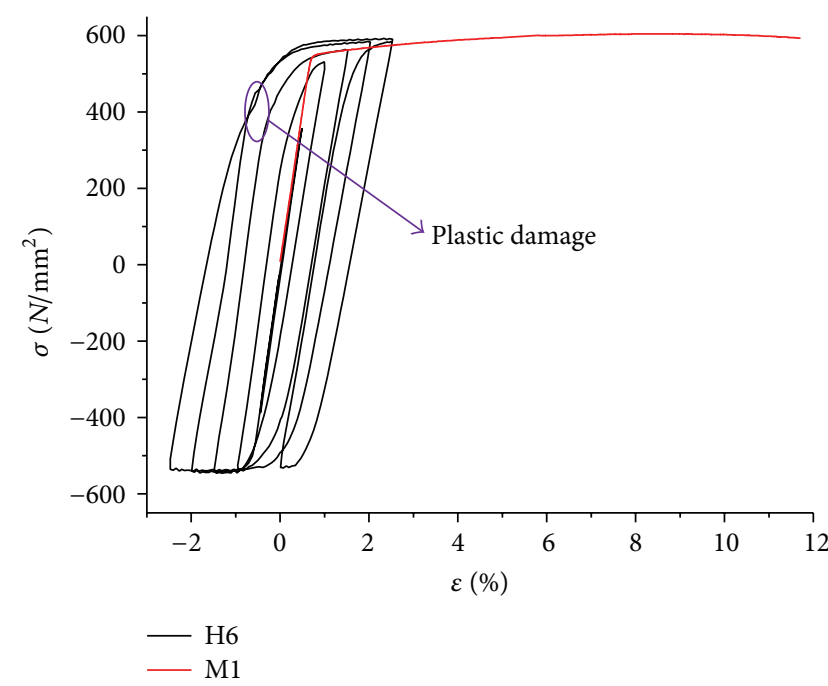

Figure 5: Comparison between monotonic and cyclic loading curves.

strain, which is largely due to two reasons. The first one is that local buckling led to a strength decrease; the second one is that the strain measured by extensometer included buckling deformation leading to the stiffness degradation. However, both the stiffness degradation and strength degradation are caused by specimen buckling damage rather than the constitutive relationship of 7A04 HSAA itself [15].

(3) For specimens H6 and H8 (first press and then pull), the tensile nominal yield stress is nearly the same with the one derived in monotonic loading. Bauschinger effect of the material is not significant.

(4) For specimens subjected to cyclic loading, the decrease range of the fracture strength is the same with the specimens under monotonic loading. The ductility of 7A04 HSAA did not decrease due to cyclic loading, which is different from the properties of steel.

(5) 7A04 HSAA showed combined hardening behavior including isotropic hardening and nonlinear kinetic hardening.

(6) Under many kinds of cyclic loading systems, the curves in Figure 6 are plump which show good hysteretic behavior of 7A04 HSAA.

Stress-strain skeleton curves were used to investigate the difference between the constitutive relationship of 7A04 HSAA under cyclic loading and the one under monotonic loading. The point on the skeleton curve is the point with the maximum stress and maximum strain in each loading cycle. Ramberg-Osgood model was adopted to fit the stress-strain skeleton curves. The formula is as follows:

$$
\frac{\Delta \varepsilon}{2}=\frac{\Delta \varepsilon_{e}}{2}+\frac{\Delta \varepsilon_{p}}{2}=\frac{\Delta \sigma}{2 E}+\left(\frac{\Delta \sigma}{2 K^{\prime}}\right)^{1 / n^{\prime}}
$$


TABLE 3: Test results of cyclic loading.

\begin{tabular}{|c|c|c|c|c|c|c|}
\hline Specimen & $f_{0.2} / \mathrm{MPa}$ & $f_{u} / \mathrm{MPa}$ & $f_{u 2} / \mathrm{MPa}$ & $\varepsilon_{1} / \%$ & $N_{c}$ & $E_{n} / \mathrm{kN} \cdot \mathrm{mm}$ \\
\hline $\mathrm{H} 1$ & 545.14 & 1 & 1 & 0.94 & 6 & 185.68 \\
\hline $\mathrm{H} 2$ & 543.56 & 615.99 & 594.53 & 0.90 & 10 & 77.75 \\
\hline $\mathrm{H} 3$ & 544.18 & 606.12 & 598.96 & 0.94 & 6 & 53.80 \\
\hline $\mathrm{H} 4$ & 542.66 & 627.07 & 597.42 & 0.95 & 6 & 117.26 \\
\hline H5 & 542.08 & 631.12 & 602.66 & 0.88 & 5 & 113.75 \\
\hline H6 & 548.83 & 604.14 & 604.03 & 0.89 & 5 & 116.57 \\
\hline $\mathrm{H} 7$ & 543.27 & 619.57 & 593.52 & 0.95 & 6 & 55.68 \\
\hline $\mathrm{H} 8$ & 530.48 & 613.02 & 587.04 & 0.87 & 6 & 55.57 \\
\hline H9 & 541.29 & 605.20 & 601.27 & 0.90 & 5 & 112.44 \\
\hline H10 & 544.15 & 618.60 & 592.09 & 0.84 & 5 & 59.52 \\
\hline H11 & 532.39 & 599.03 & 580.14 & 0.98 & 6 & 61.24 \\
\hline H12 & 542.88 & 615.72 & 590.75 & 0.87 & 7 & 95.67 \\
\hline H13 & 542.89 & 623.28 & 595.65 & 0.91 & 5 & 121.96 \\
\hline H14 & 550.99 & 628.30 & 613.66 & 0.93 & 6 & 173.97 \\
\hline H15 & 554.52 & 612.95 & 599.64 & 1.00 & 5 & 23.17 \\
\hline
\end{tabular}

TABLE 4: Cyclic hardening parameters.

\begin{tabular}{lccc}
\hline Specimen & $E / \mathrm{MPa}$ & $K^{\prime /} \mathrm{MPa}$ & $n^{\prime}$ \\
\hline H3 & 73970 & 714.24 & 0.052 \\
H4 & 72463 & 798.89 & 0.071 \\
H5 & 79870 & 822.35 & 0.078 \\
H6 & 79820 & 761.11 & 0.063 \\
H10 & 84678 & 734.98 & 0.056 \\
H12 & 81132 & 839.89 & 0.087 \\
H13 & 76688 & 734.01 & 0.062 \\
H15 & 69647 & 723.16 & 0.053 \\
\hline
\end{tabular}

In order to facilitate the fitting process, (3) is simplified as follows:

$$
\varepsilon=\frac{\sigma}{E}+\left(\frac{\sigma}{K^{\prime}}\right)^{1 / n^{\prime}}
$$

The initial elastic modulus $E$ of 7A04 HSAA and the parameters of R-O model $\left(K^{\prime}\right.$ and $\left.n^{\prime}\right)$ are shown in Table 4. Figure 7 shows the comparison between the typical fitting curves and monotonic curves. From Figure 7, the RambergOsgood model can fit the stress-strain skeleton curves of 7A04 HSAA fairly well. With the increase of strain amplitude, the cyclic hardening effect is more and more obvious. Combined with the data in Tables 2 and 3, the cyclic hardening effect could increase the ultimate strength by $3 \%$. The strength increasing degree by cyclic hardening effect of 7A04 HSAA is less than steel.

\subsection{Test Phenomenon and Failure Modes}

3.4.1. Macroscopic Failure Modes. In the loading process, there are no visible deformation and necking of the specimens before its failure. In the cyclic loading, when the compressive strain was larger than $2.0 \%$, the obvious local buckling could be observed as shown in Figure 8. The failure process of the specimen is very sudden with relatively small fracture strain. The failure mode is shown in Figure 9. The fracture surface forms a 45-degree angle with the direction of tensile stress. The fracture section is very even without deformation and shrinkage.

3.4.2. Microfailure Modes. Fracture surface was observed by scanning electron microscope (SEM) with magnifications of 2,000 times. The microfailure modes are shown in Figure 10. The specimens in Figures 10(a), 10(b), and 10(c) have many round or oval dimples which have better ductility than the specimen in Figure 10(d) (H1). There is obvious fish scale cleavage observed in the fracture surface of $\mathrm{H} 1$ which shows typical characteristic of fatigue failure.

\section{Numerical Simulation of the Cyclic Loading Experiments}

In order to provide a foundation for the analysis of high strength aluminum alloy structures in seismic design, finite element analysis software ABAQUS [16] was used to simulate the cyclic experiments. To describe the elastoplastic response completely, von Mises rule was adopted for flow rule and a combined model including isotropic hardening and kinematic hardening was adopted for hardening criterion according to the research work [13]. Figure 11 shows the schematic diagram of the isotropic hardening and kinematic hardening.

4.1. Isotropic Hardening. Isotropic hardening describes the variation of the size of yield surface $\sigma^{0}$, which is a function of equivalent plastic strain $\varepsilon^{p}$, and is shown in the following equation:

$$
\sigma^{0}=\left.\sigma\right|_{0}+Q_{\infty}\left(1-e^{-b_{\text {iso }} \varepsilon^{p}}\right)
$$

where $\left.\sigma\right|_{0}$ is the yield stress when the equivalent plastic strain equals zero; according to the research work [17], take 


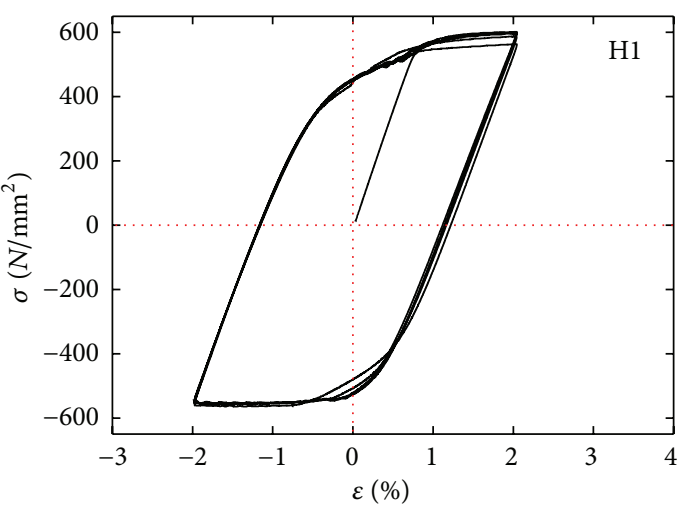

(a) $\mathrm{H} 1$

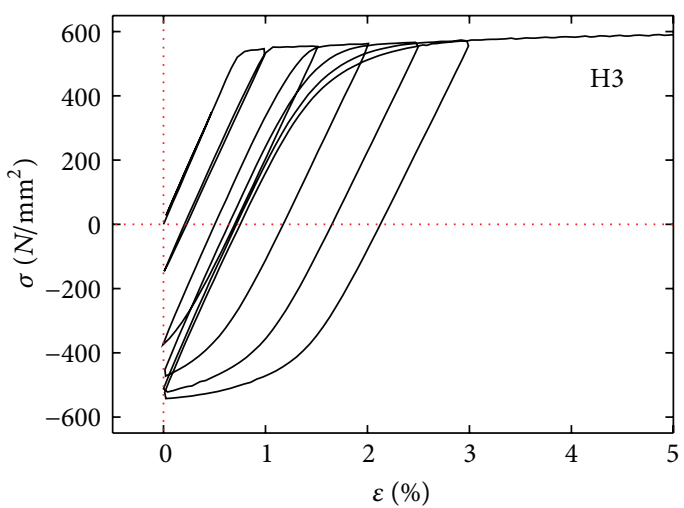

(c) $\mathrm{H} 3$

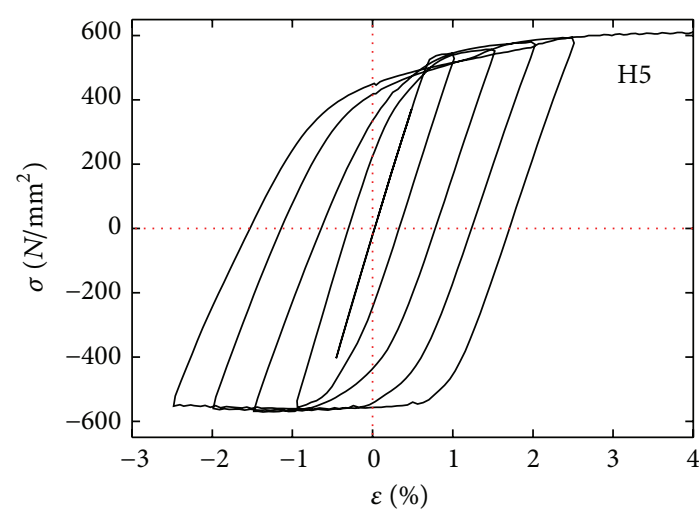

(e) $\mathrm{H} 5$

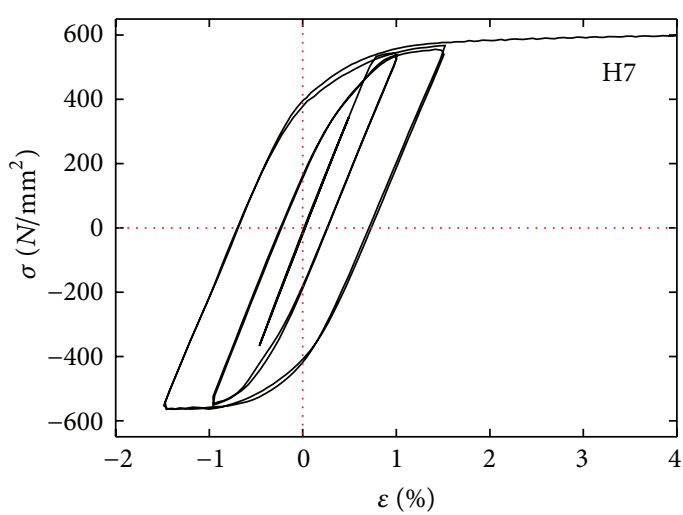

(g) $\mathrm{H} 7$

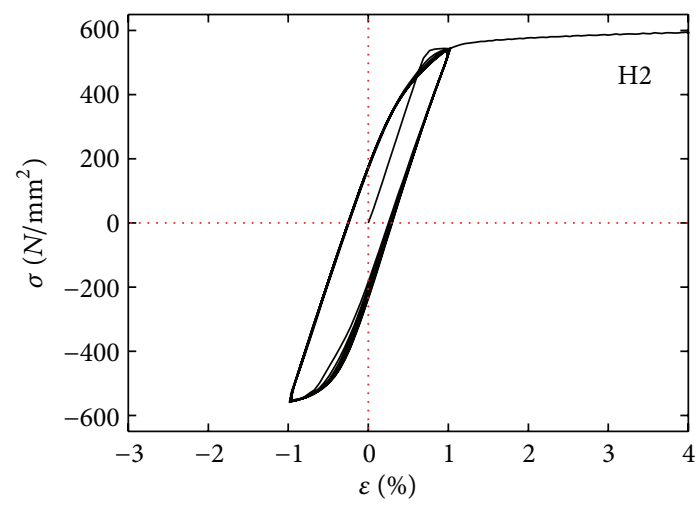

(b) $\mathrm{H} 2$

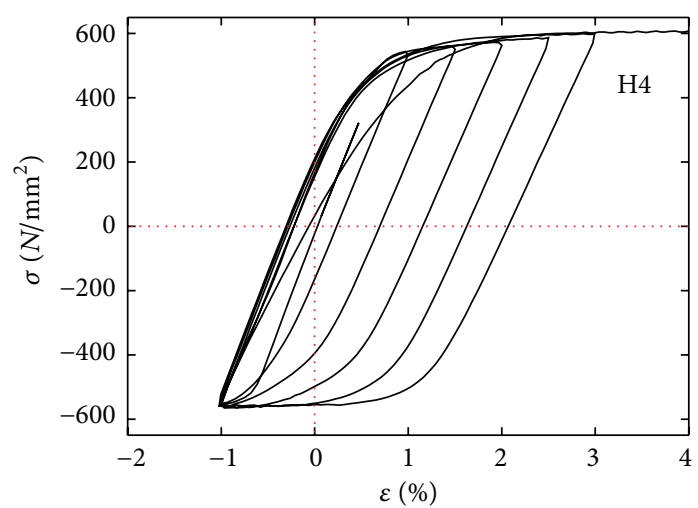

(d) $\mathrm{H} 4$

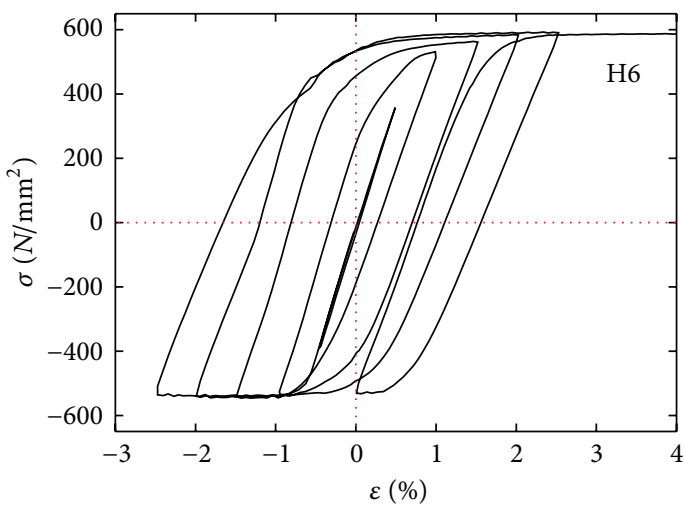

(f) $\mathrm{H} 6$

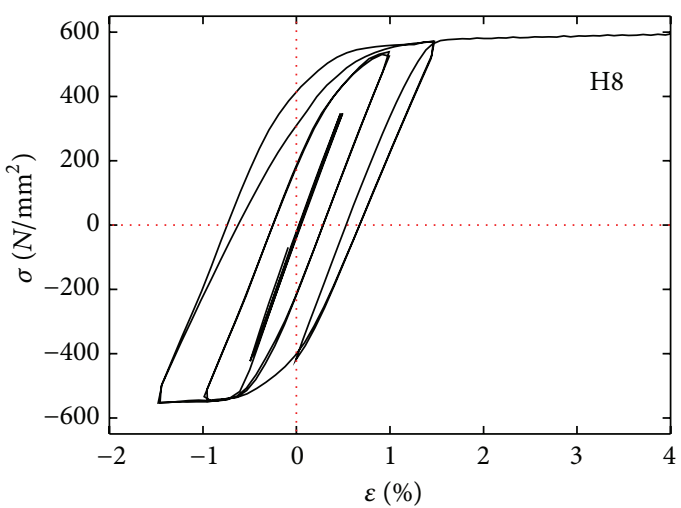

(h) $\mathrm{H} 8$

FIgURE 6: Continued. 


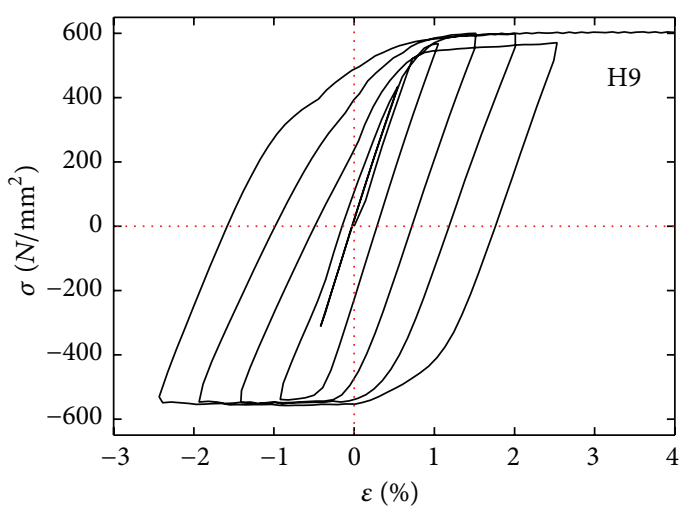

(i) $\mathrm{H} 9$

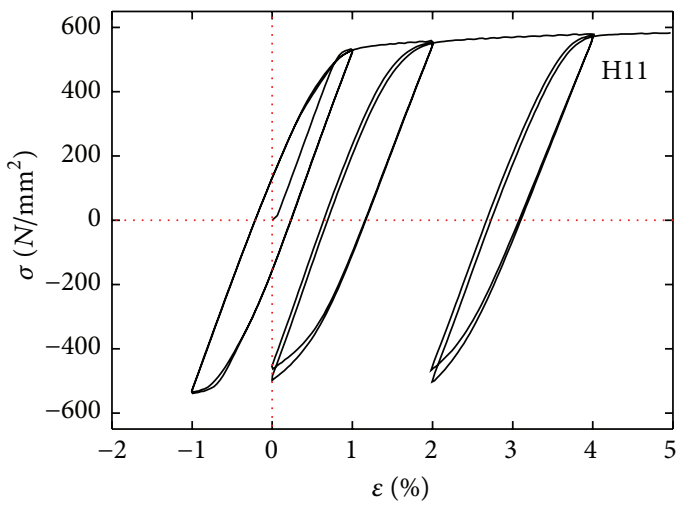

(k) H11

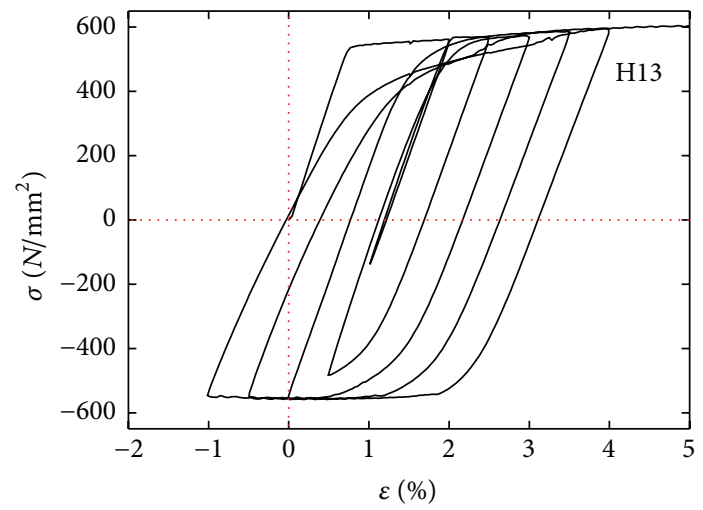

(m) $\mathrm{H} 13$

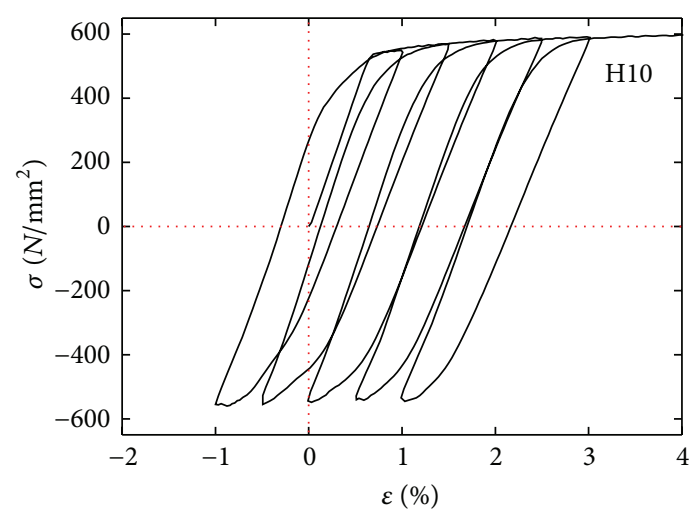

(j) $\mathrm{H} 10$

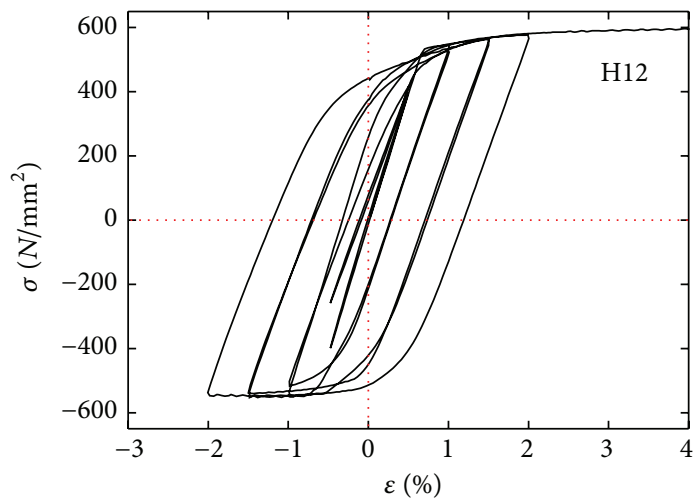

(l) H12

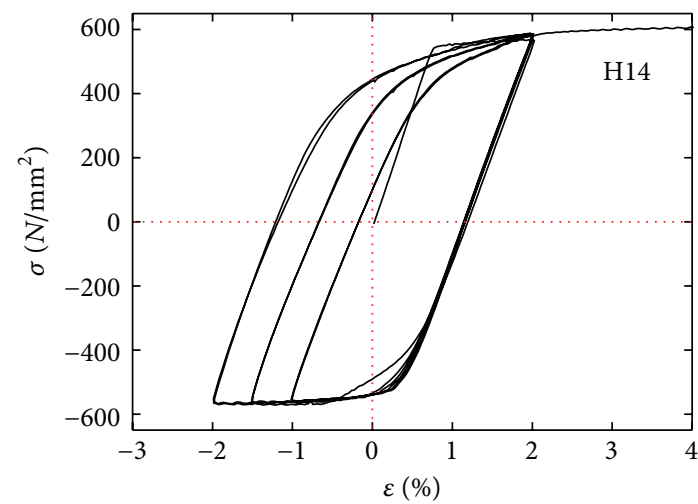

(n) $\mathrm{H} 14$

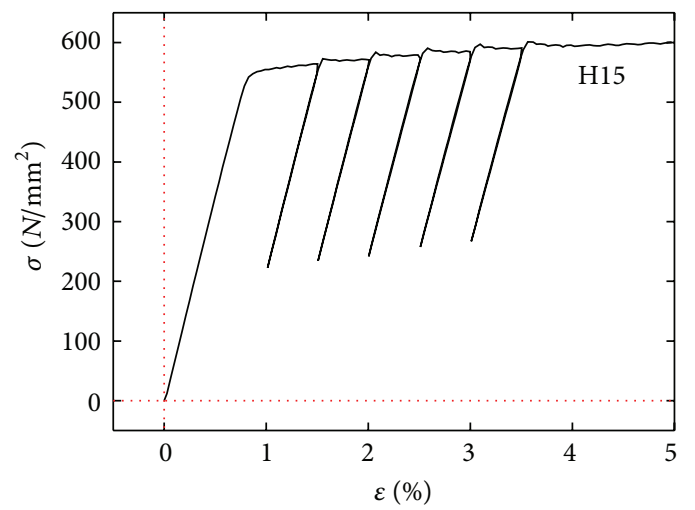

(o) H15

FIGURE 6: Stress-strain curves of 7A04 HSAA under cyclic loading. 


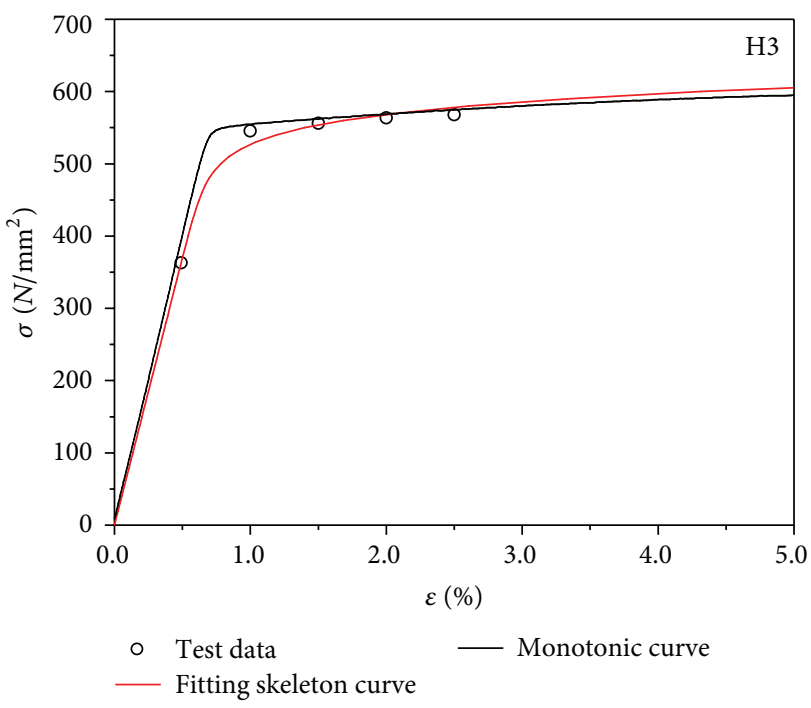

(a) $\mathrm{H} 3$

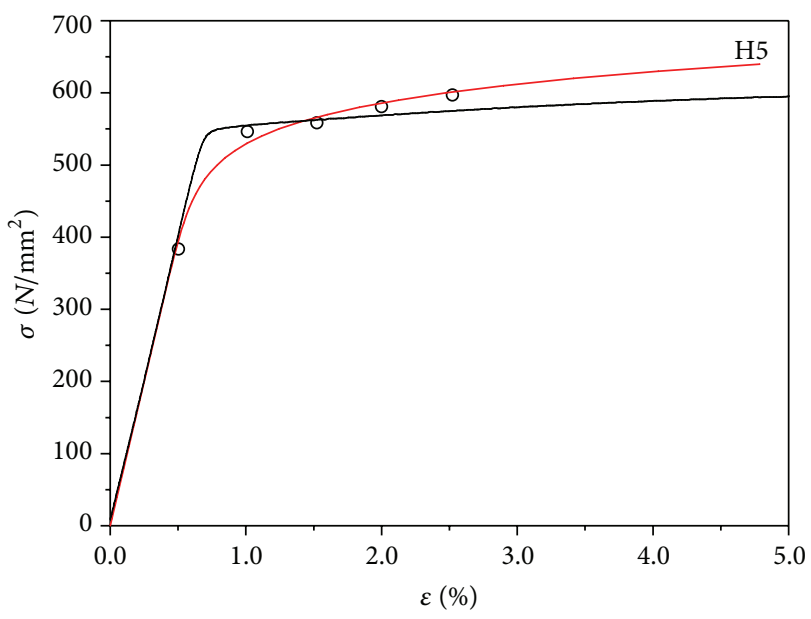

- Test data

— Monotonic curve

— Fitting skeleton curve

(c) $\mathrm{H} 5$

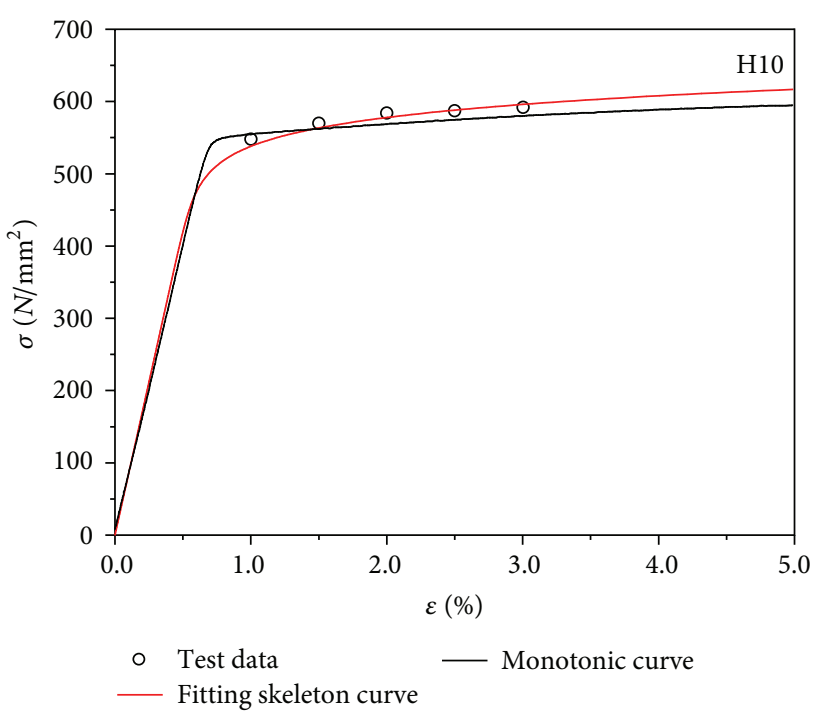

(e) H10

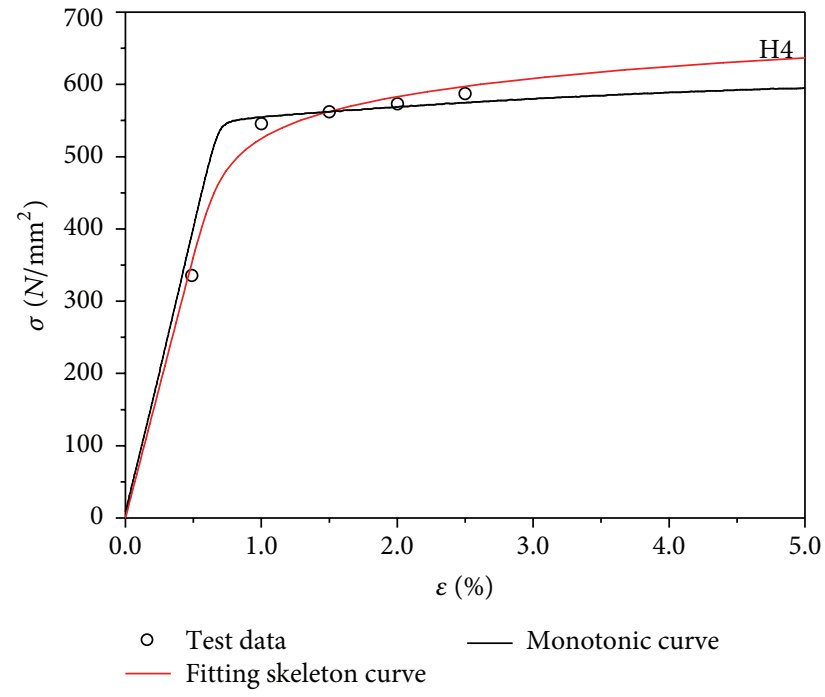

(b) $\mathrm{H} 4$

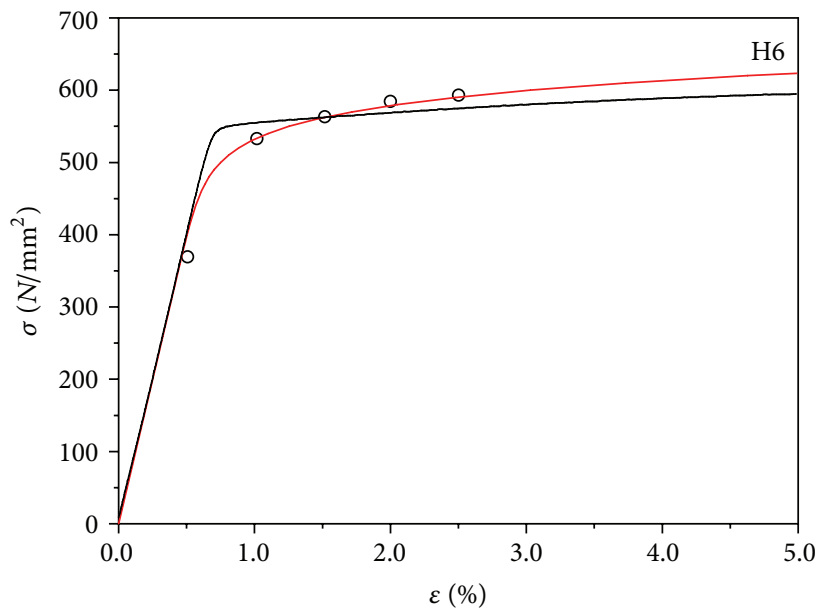

- Test data Fitting skeleton curve

(d) $\mathrm{H} 6$

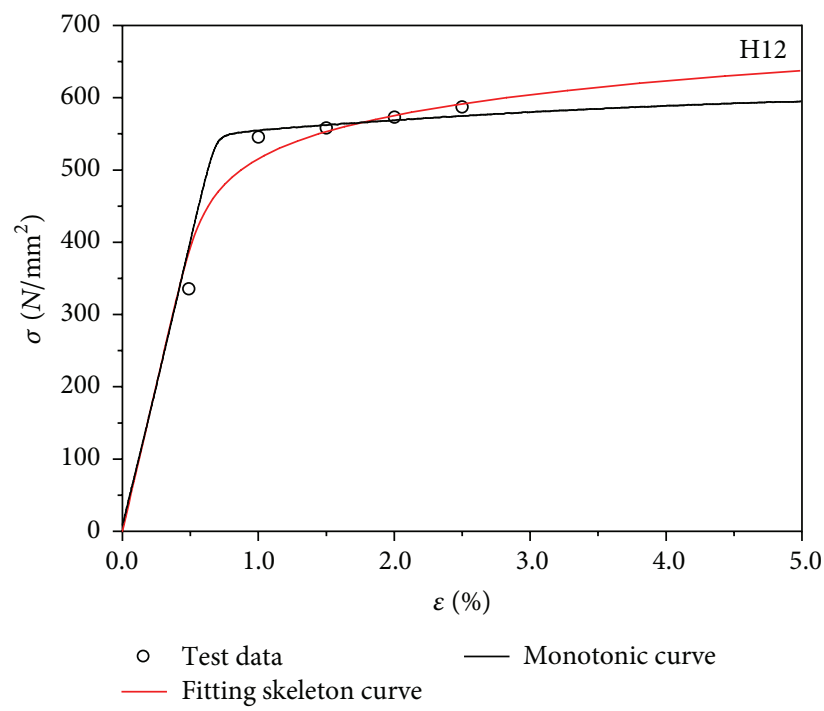

(f) $\mathrm{H} 12$

FIgURE 7: Continued. 


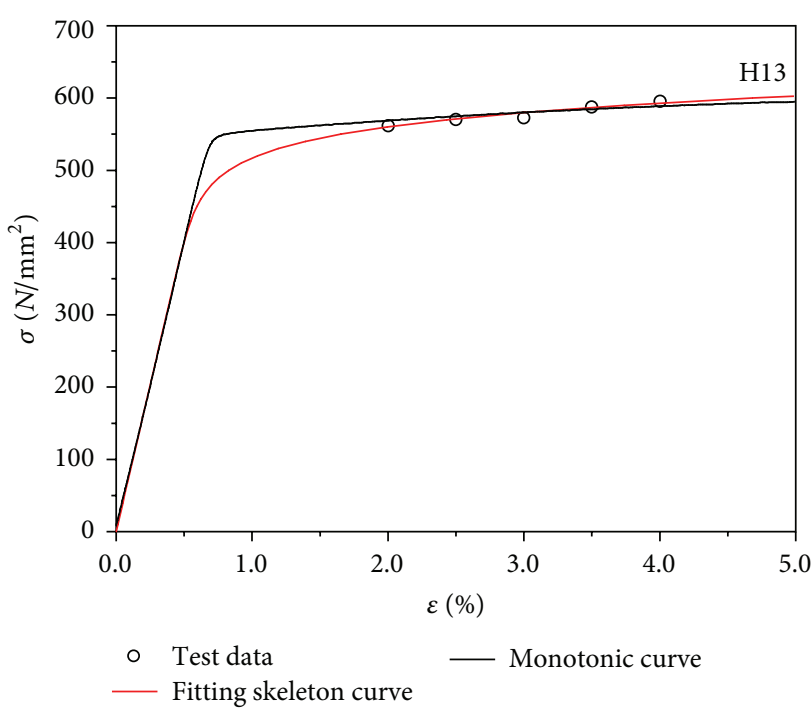

(g) $\mathrm{H} 13$

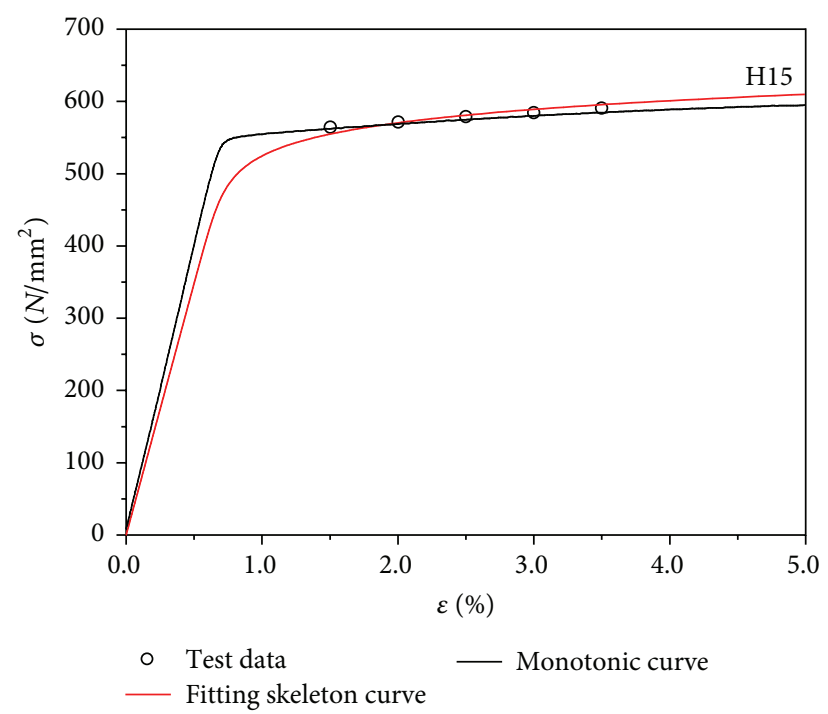

(h) $\mathrm{H} 15$

FIGURE 7: The comparison between cyclic skeleton curves and monotonic loading curves.

TABLE 5: Parameters of 7A04 aluminum alloy in the combined model.

\begin{tabular}{lccccccccc}
\hline Parameter & $\left.\sigma\right|_{0} / \mathrm{MPa}$ & $Q_{\infty}$ & $b_{\text {iso }}$ & $C_{\text {kin, }, 1} / \mathrm{MPa}$ & $\gamma_{1}$ & $C_{\text {kin }, 2} / \mathrm{MPa}$ & $\gamma_{2}$ & $C_{\text {kin, } 3} / \mathrm{MPa}$ & $\gamma_{3}$ \\
\hline Value & 521.11 & 60.20 & 26.63 & 83.92 & 0.78 & 33.33 & 0.80 & 12.74 & 0.88 \\
\hline
\end{tabular}

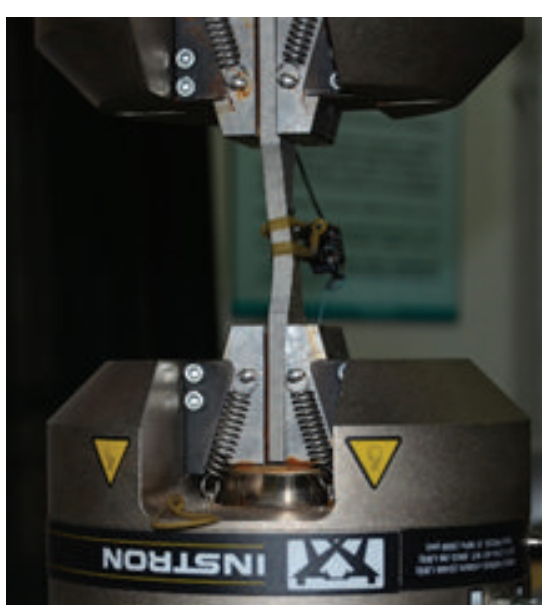

FIGURE 8: Buckling by compression.

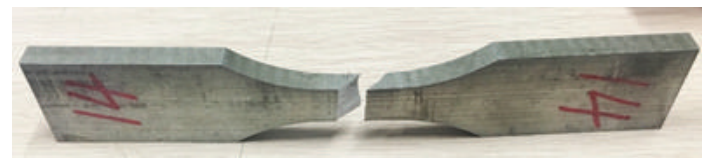

Figure 9: Macroscopic failure modes of the specimen.

$\sigma_{0.01}$ as $\left.\sigma\right|_{0}$ for nonlinear metal material; $Q_{\infty}$ and $b_{\text {iso }}$ are undetermined parameters which mean the maximum change in the size of the yield surface and rate at which the size of the yield surface changes as plastic strain increases, respectively; $\sigma_{i}^{0}$ is the size of the yield surface in $i$ th cycle which is defined as the following equation:

$$
\sigma_{i}^{0}=\frac{\sigma_{i}^{t}-\sigma_{i}^{c}}{2}
$$

where $\sigma_{i}^{t}$ is the maximum tensile stress and $\sigma_{i}^{c}$ is the maximum compressive stress (Figure 11(a)).

The equivalent plastic strain $\varepsilon_{i}^{p}$ is defined as

$$
\begin{aligned}
\varepsilon_{i}^{p} & =\frac{1}{2}(4 i-3) \Delta \varepsilon_{p}, \\
\Delta \varepsilon_{p} & \approx \Delta \varepsilon-\frac{2 \sigma_{1}^{t}}{E},
\end{aligned}
$$

where $\Delta \varepsilon_{p}$ is the plastic strain range. $Q_{\infty}$ and $b_{\text {iso }}$ in (5) can be calibrated through the data pair $\left(\sigma_{i}^{0}, \varepsilon_{i}^{p}\right)$ including the data pair $\left(\left.\sigma\right|_{0}, 0\right)$. The parameters of isotropic hardening component are listed in Table 5.

4.2. Nonlinear Kinematic Hardening. Kinematic hardening describes the variation of backstress $\alpha_{k}$ which is the function of plastic strain $\varepsilon^{p}$ in a stabilized cycle, as is shown in (8):

$$
\begin{aligned}
\alpha_{k} & =\frac{C_{\mathrm{kin}, k}}{\gamma_{k}}\left(1-e^{-\gamma_{k} \varepsilon^{p}}\right)+\alpha_{k, 1} e^{-\gamma_{k} \varepsilon^{p}}, \\
\alpha & =\sum_{k=1}^{N} \alpha_{k},
\end{aligned}
$$

where $C_{\mathrm{kin}, k}$ and $\gamma_{k}$ are undetermined parameters which mean initial kinematic hardening modulus and rate at which 


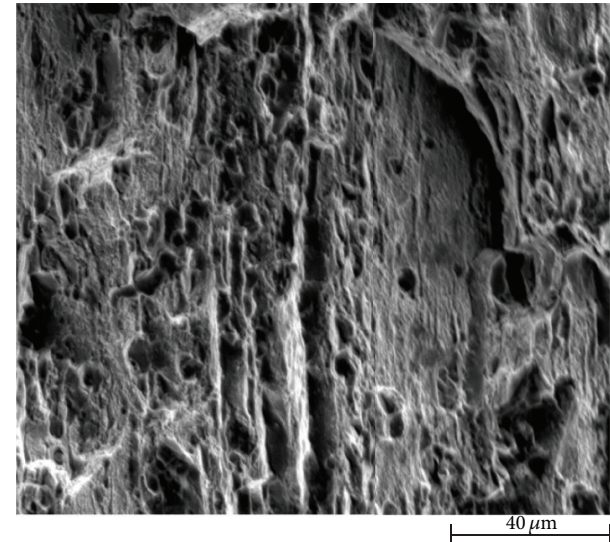

(a) Monotonic loading (M1)

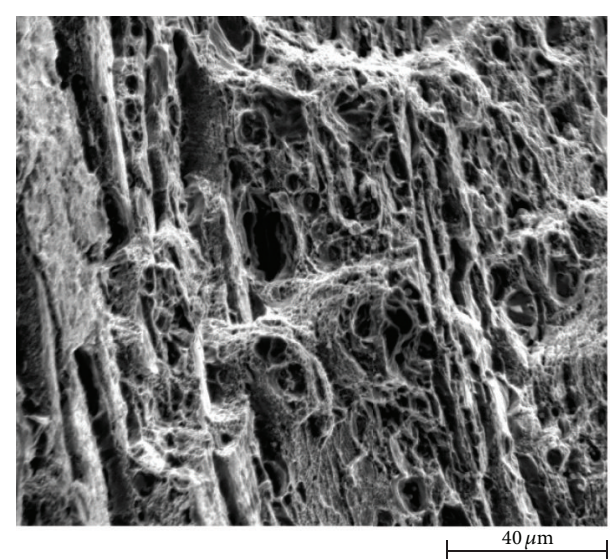

(c) Gradual cyclic loading (H5)

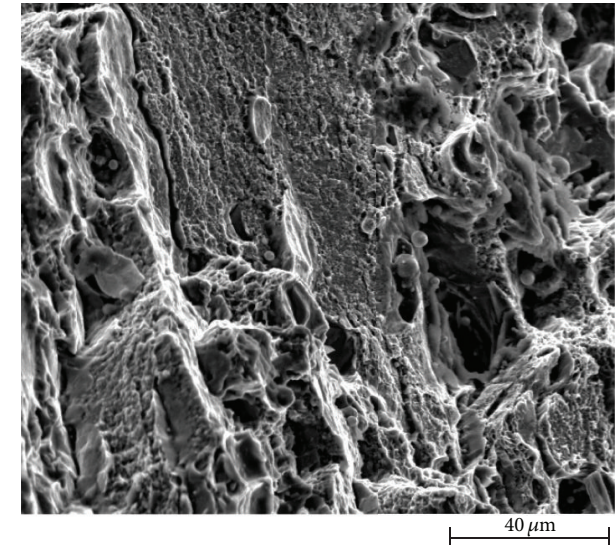

(b) Constant-amplitude cyclic loading (H2)

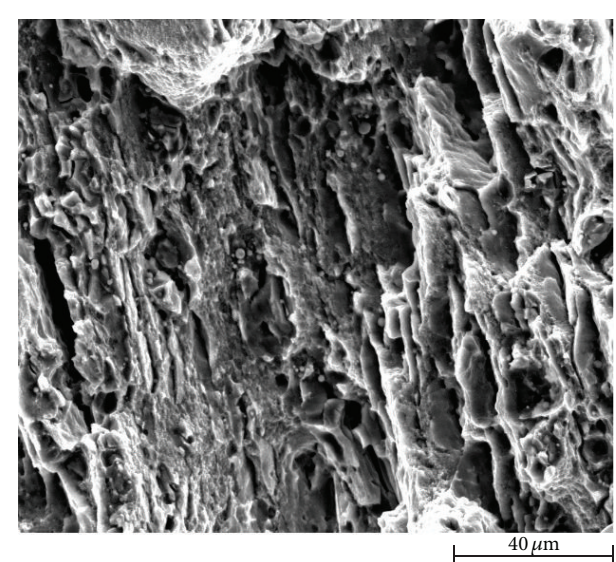

(d) Fatigue failure (H1)

FIGURE 10: Microfailure modes of fracture surface.

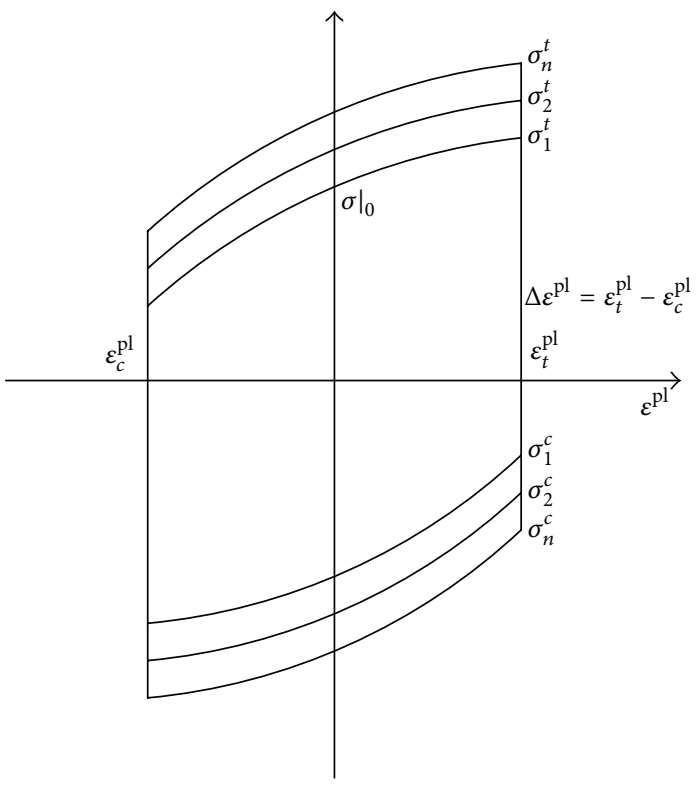

(a) Isotropic hardening

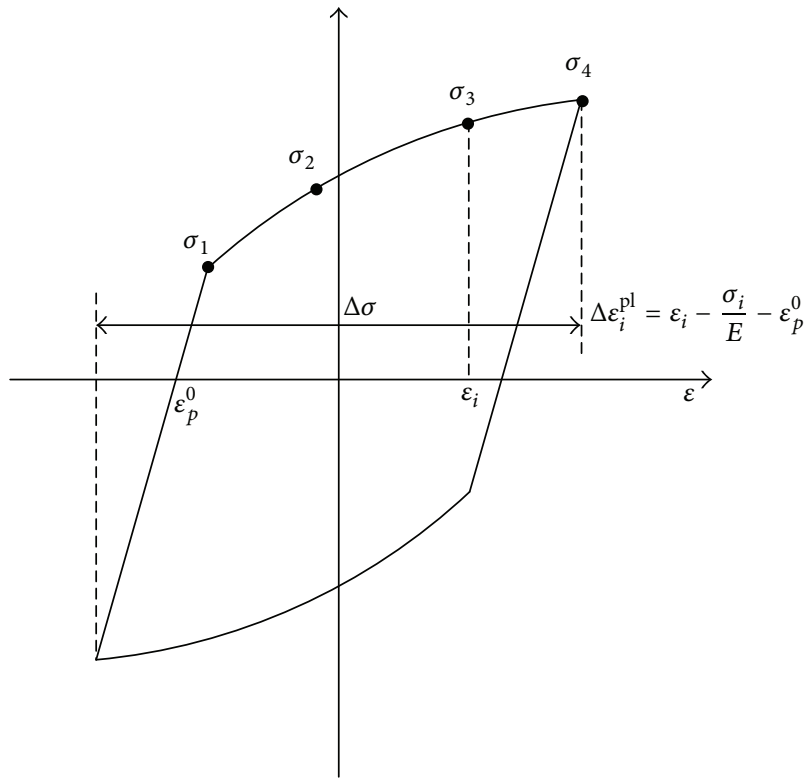

(b) Kinematic hardening

FIGURE 11: Schematic diagram of the isotropic hardening and kinematic hardening. 

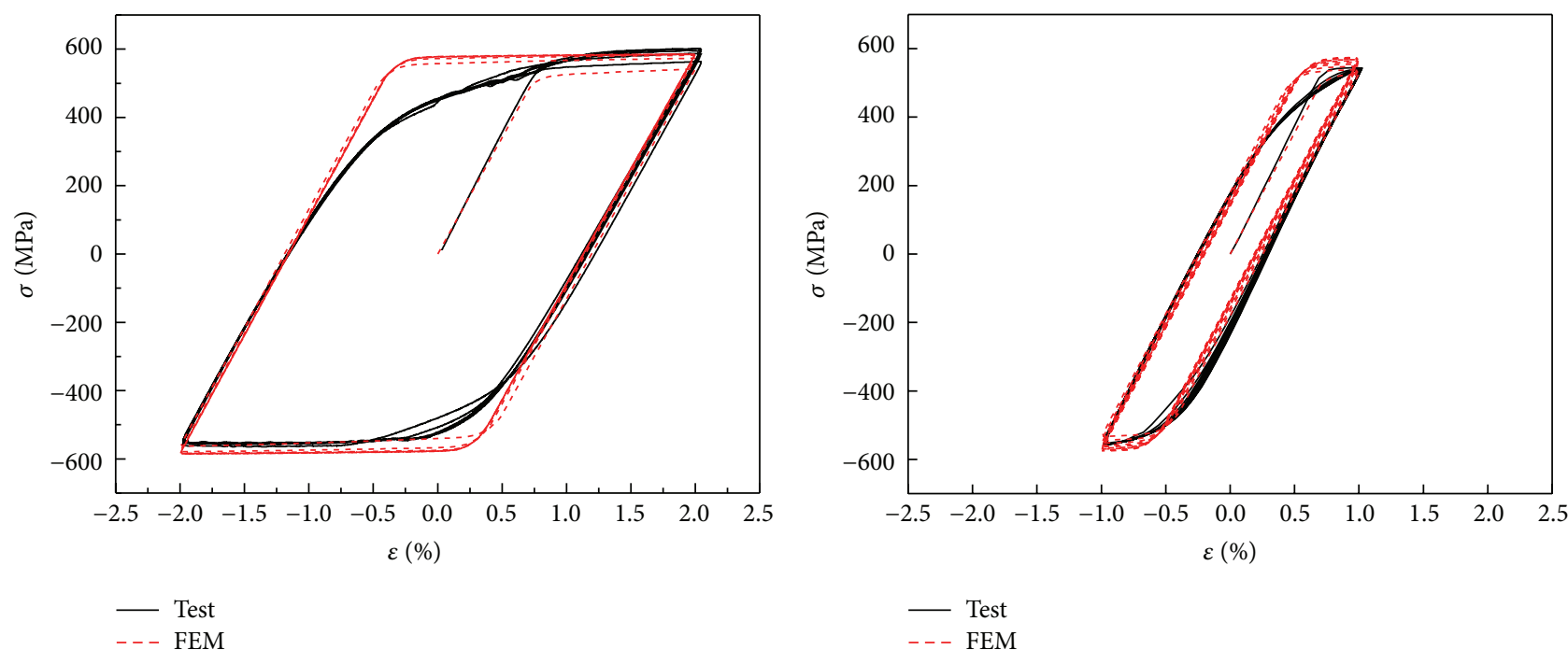

(a) $\mathrm{H} 1$

(b) $\mathrm{H} 2$
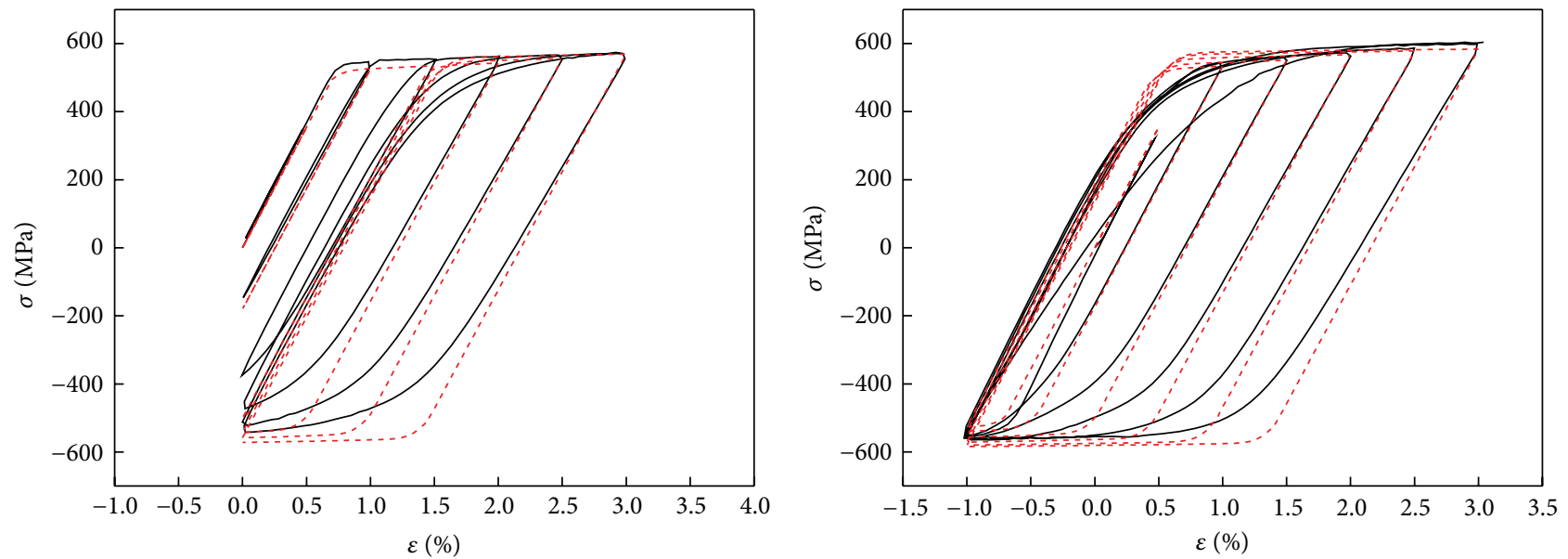

— Test

- - - FEM

- Test

(c) $\mathrm{H} 3$

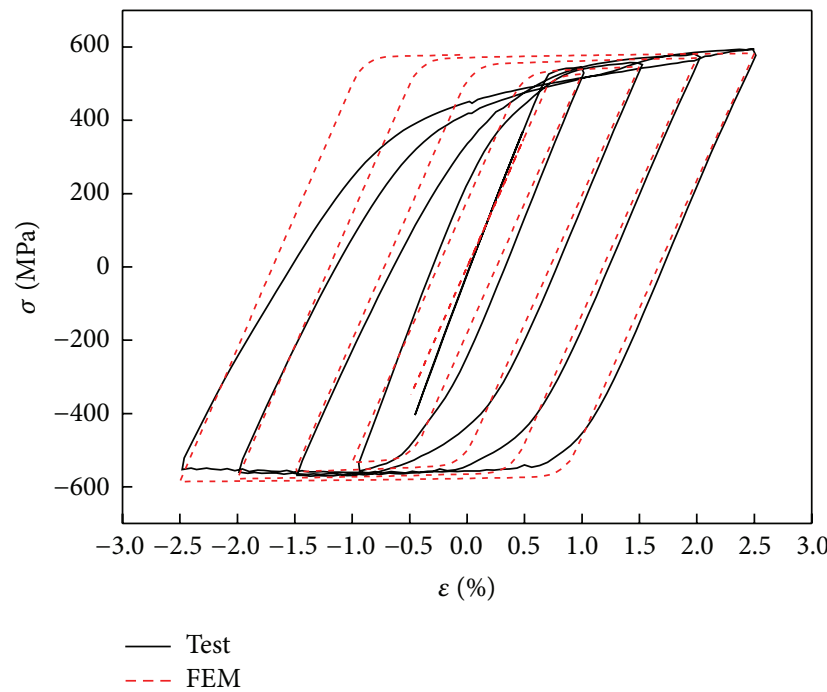

(e) $\mathrm{H} 5$

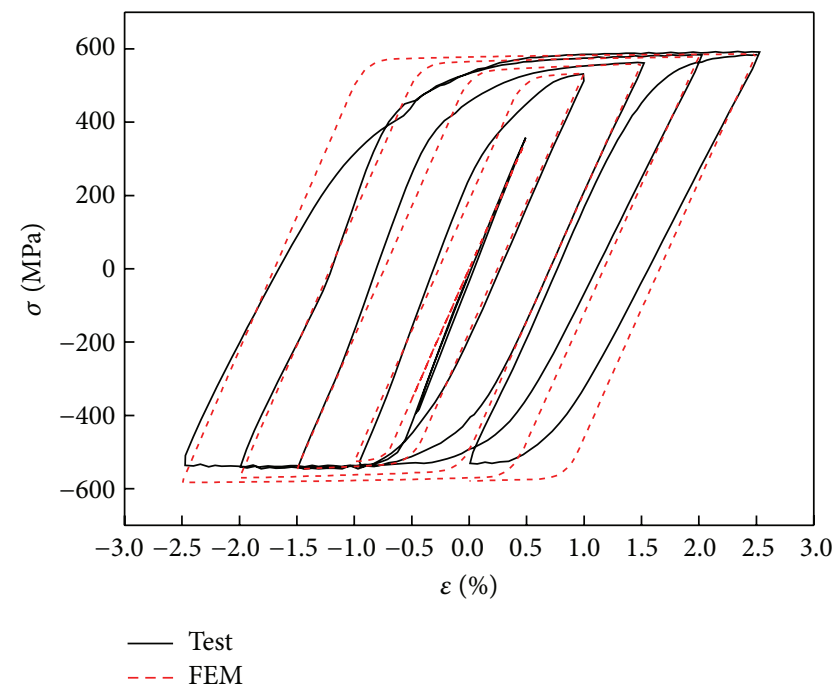

(f) $\mathrm{H6}$

FIgure 12: Continued. 

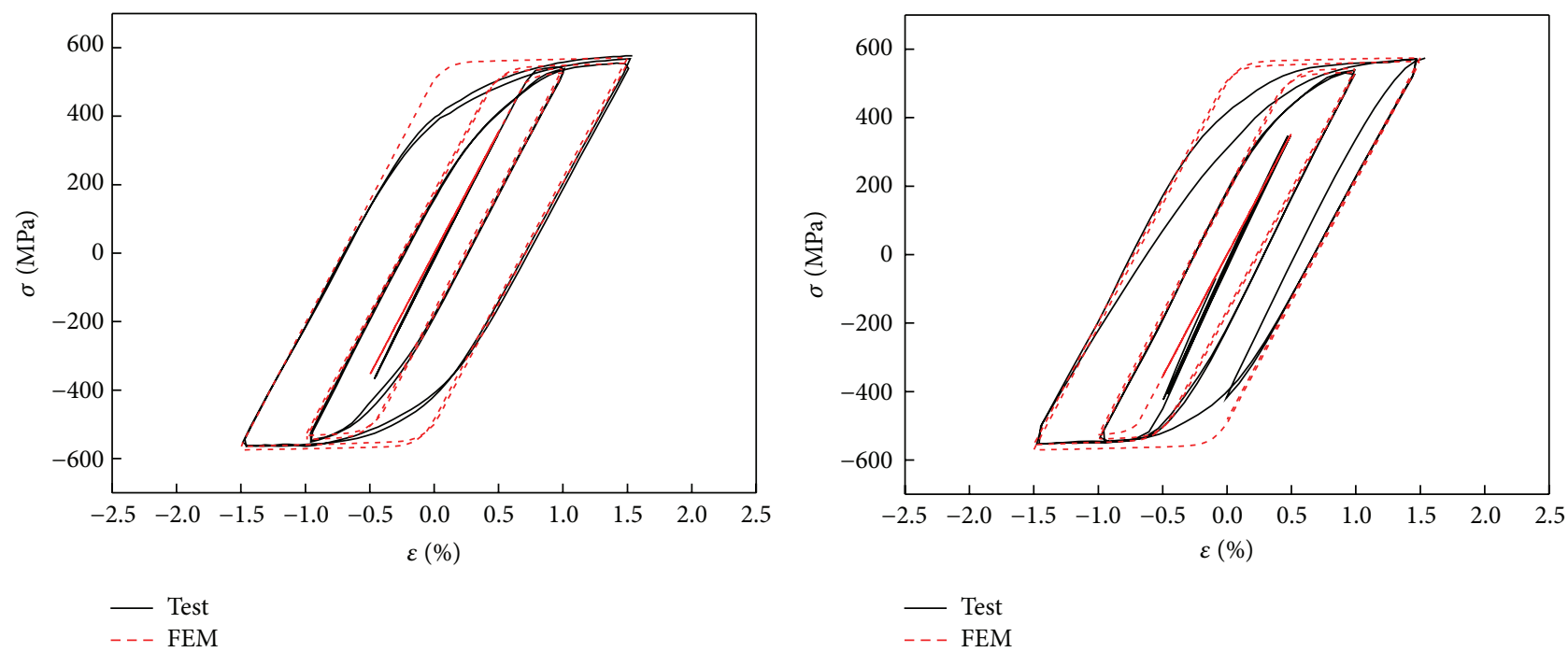

(g) $\mathrm{H} 7$
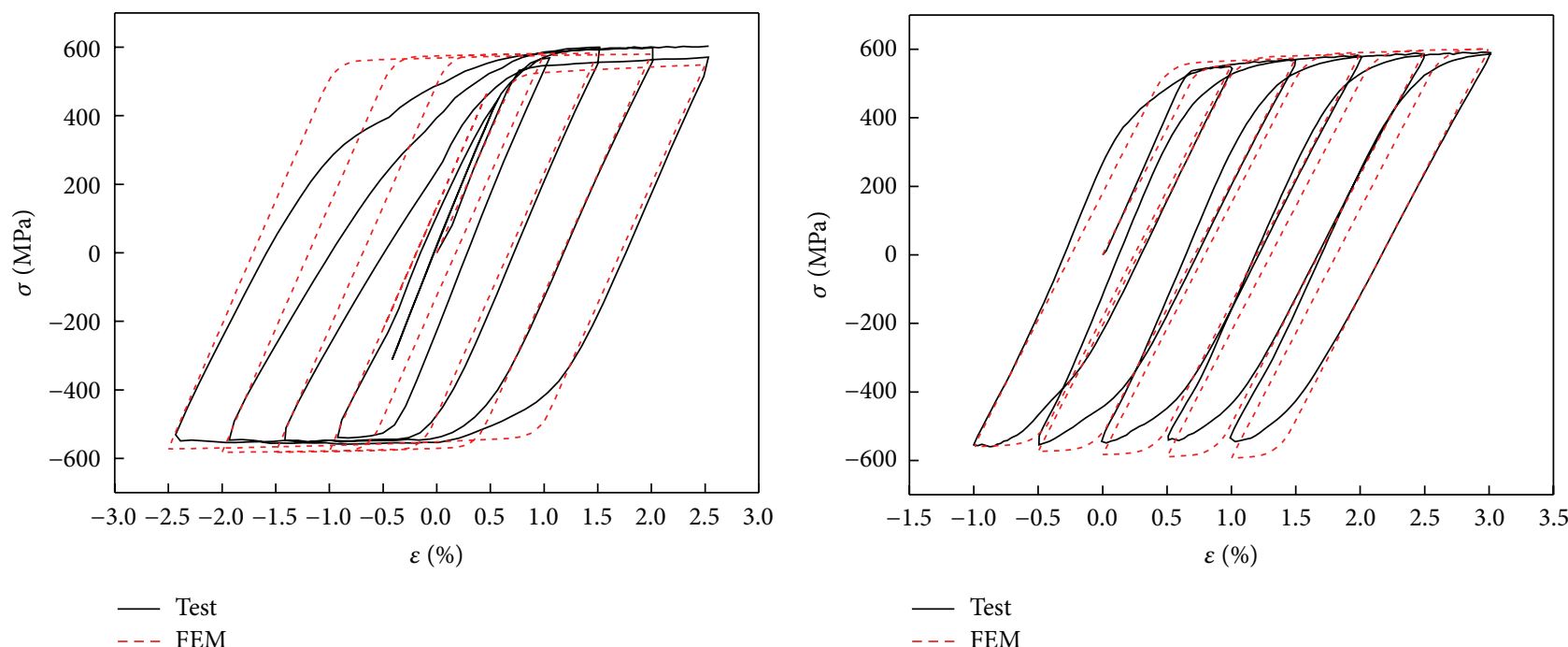

(i) $\mathrm{H} 9$
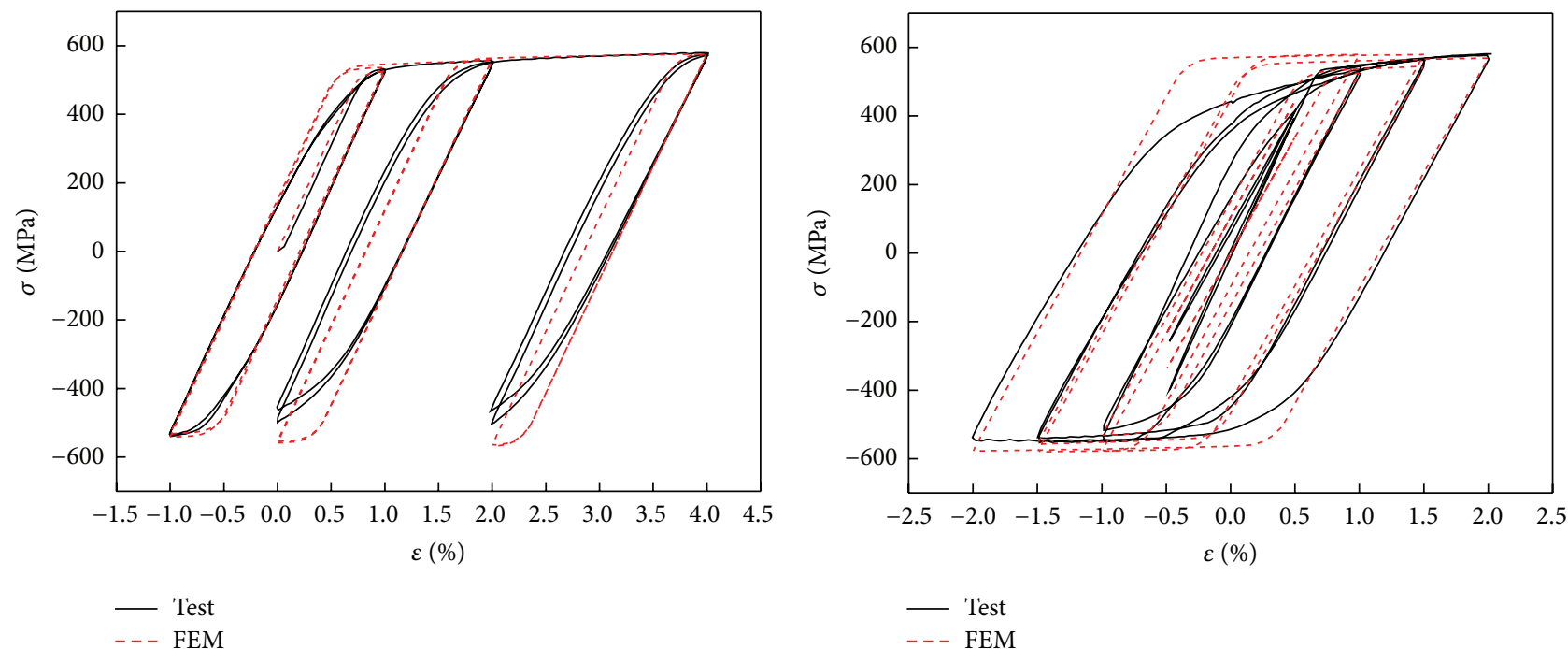

(k) H11

(l) H12

Figure 12: Continued. 


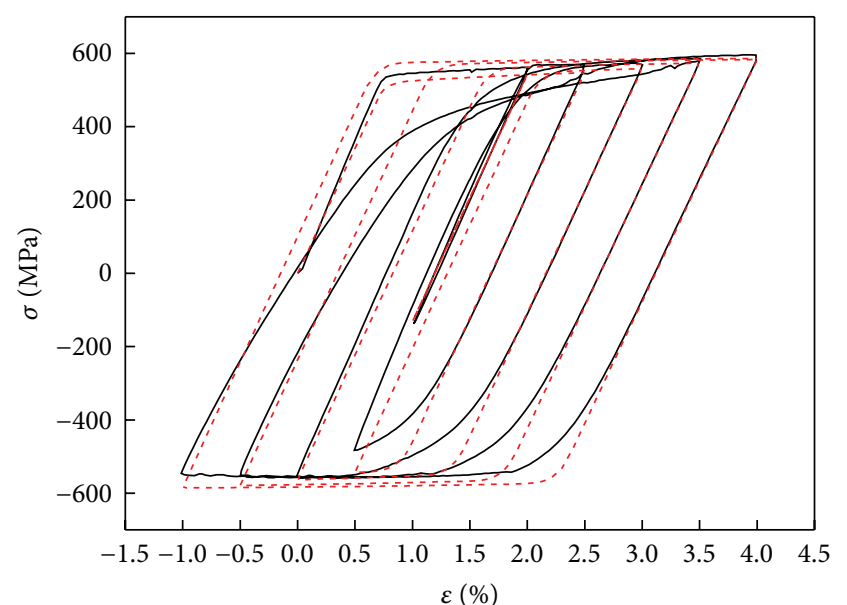

- Test

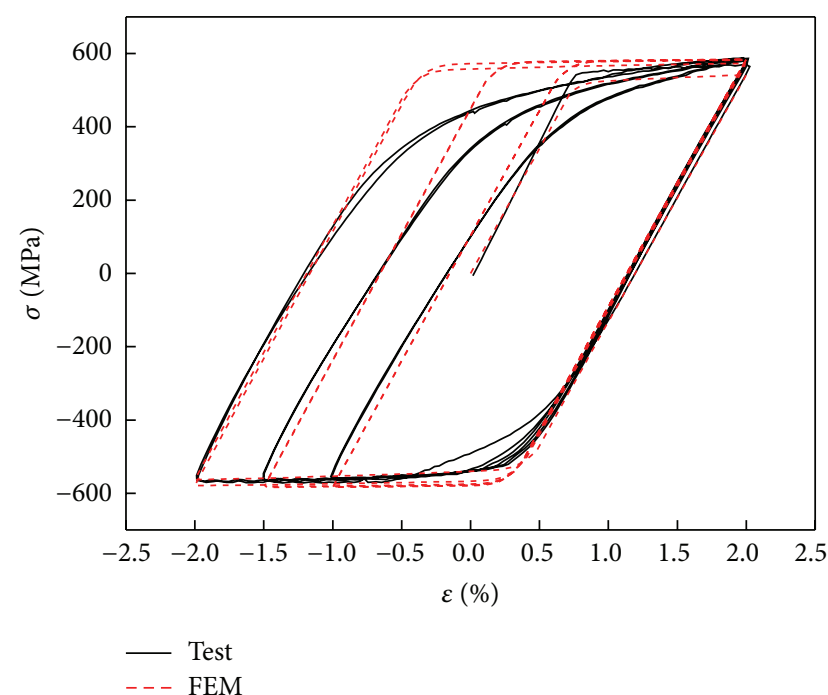

(n) $\mathrm{H} 14$

-- FEM

(m) $\mathrm{H} 13$

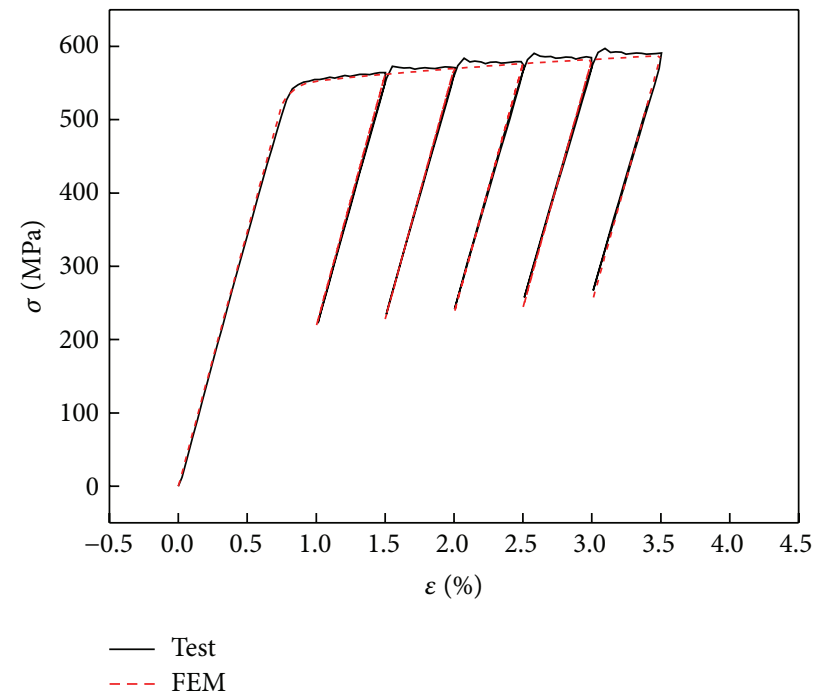

(o) $\mathrm{H} 15$

FIGURE 12: Comparison analysis between test curves and FE curves.

the kinematic hardening modulus varies with increasing plastic deformation, respectively. $\alpha_{k}$ is $k$ th backstress and $\alpha_{k, 1}$ is $k$ th backstress of the first data point, $k=1,2,3, \ldots, N$.

The multiple backstress superposition method (9) is adopted for fitting the curve more accurately. In the current paper, $k$ equals 3 in (9).

Plastic strain $\varepsilon_{i}^{\mathrm{pl}}$ in data pairs $\left(\sigma_{i}, \varepsilon_{i}^{\mathrm{pl}}\right)$ is shifted as

$$
\varepsilon_{i}^{\mathrm{pl}}=\varepsilon_{i}-\frac{\sigma_{i}}{E}-\varepsilon_{p}^{0},
$$

where $\varepsilon_{i}^{\mathrm{pl}}$ is the plastic strain value when the curve intercepts the strain axis and $\varepsilon_{1}^{\mathrm{pl}}$ equals zero. For each data pair $\left(\sigma_{i}, \varepsilon_{i}^{\mathrm{pl}}\right)$, backstress could be obtained from (11):

$$
\alpha_{i}=\sigma_{i}-\sigma^{s}
$$

where $\sigma^{s}=\left(\sigma_{1}+\sigma_{n}\right) / 2$; that is, $\sigma^{s}$ is average value of the first data $\sigma_{1}$ and last data $\sigma_{n}$. Lots of data pairs $\left(\alpha_{i}, \varepsilon_{i}^{\mathrm{pl}}\right)$ were used to calibrate the parameters $C_{\mathrm{kin}, k}$ and $\gamma_{k}$ which are obtained in Table 5.

4.3. FE Analysis. The comparison between the FE results and test results is shown in Figure 12. The simulated curves fit well with the experimental curves. However, because of unknown imperfections in the test specimens, the FE results overestimate the stress in certain strain region. Because of the model assumption in ABAQUS, in the upper left corner area, the simulated curves have little difference with the test curves which is also found in research work $[18,19]$.

In general, the parameters of 7A04 HSAA in the combined model can be used in the analysis of 7A04 HSAA structures or members under cyclic loading. 


\section{Conclusion}

Experimental investigation of 7A04 HSAA under monotonic loading and cyclic loading was conducted and a corresponding FE model was established in the current paper. From all above research, main conclusions can be obtained as follows:

(1) There are no visible deformation and necking of the specimens under monotonic loading and cyclic loading. The failure process is very sudden with a loud sound. The fracture surface was very even and forms a 45-degree angle with the direction of tensile stress. And the fracture surface was observed by SEM.

(2) By hysteretic curves, the hysteretic behavior of 7A04 HSAA was investigated. The material shows typical cyclic hardening effect; however, its Bauschinger effect is not significant. For most specimens, the stiffness degradation and strength degradation occurred after $1 \%$ compressive strain. The ductility of 7A04 HSAA did not decrease due to cyclic loading. And it shows combined hardening behavior including isotropic hardening and nonlinear kinetic hardening.

(3) The stress-strain skeleton curves were fitted according to Ramberg-Osgood model. And the cyclic hardening parameters of the skeleton curves were determined. The comparison was conducted between cyclic loading skeleton curves and monotonic loading curves.

(4) The curves simulated by ABAQUS fit well with the experimental curves and the cyclic hardening parameters based on Chaboche model derived in the current paper can be used in engineering practice.

(5) This paper supplies a basis for accurate calculation of 7A04 HSAA structures under cyclic loading.

\section{Nomenclature}

$f_{0.2}$ : Nominal yield stress (stress at $0.2 \%$ plastic strain)

$f_{u}$ : Ultimate strength

$f_{u 2}$ : Fracture strength

$\varepsilon_{1}$ : $\quad$ Strain when stress is $f_{0.2}$

$\varepsilon_{u}$ : Strain when stress is $f_{u}$

$\varepsilon_{2}: \quad$ Fracture strain when stress is $f_{u 2}$

$\Delta \varepsilon$ : Total strain amplitude

$\Delta \varepsilon_{e}:$ Elastic strain amplitude

$\Delta \varepsilon_{p}$ : Plastic strain amplitude

$\Delta \sigma$ : Stable stress amplitude

$E$ : Initial elastic modulus of aluminum alloy

$K^{\prime}$ : Cyclic strength coefficient

$n^{\prime}$ : Cyclic strain-hardening exponent

$E_{n}$ : Hysteretic energy

$N_{c}$ : Hysteretic loops

$n$ : Strain-hardening coefficient in R-O model

$\sigma^{0}$ : Size of yield surface

$\varepsilon^{p}: \quad$ Equivalent plastic strain $\left.\sigma\right|_{0}: \quad$ Yield stress when the equivalent plastic strain equals zero

$\sigma_{0.01}$ : Stress at $0.01 \%$ plastic strain

$Q_{\infty}$ : Maximum change in the size of the yield surface

$b_{\text {iso }}$ : Rate at which the size of the yield surface changes as plastic strain increases

$\sigma_{i}^{0}: \quad$ Size of the yield surface in $i$ th cycle

$\sigma_{i}^{t}: \quad$ Maximum tensile stress

$\sigma_{i}^{c}: \quad$ Maximum compressive stress

$C_{\text {kin }, k}$ : Initial kinematic hardening modulus

$\gamma_{k}$ : $\quad$ Rate at which the kinematic hardening modulus varies with increasing plastic deformation

$\alpha_{k}: \quad k$ th backstress

$\alpha_{k, 1}: \quad k$ th backstress of the first data point

$\sigma^{s}: \quad$ Average value of the first data $\sigma_{1}$ and last data $\sigma_{n}$

$\varepsilon_{i}^{\mathrm{pl}}$ : The plastic strain value when the curve intercepts the strain axis.

\section{Competing Interests}

The authors declare that they have no competing interests.

\section{Acknowledgments}

The paper is supported by the National Natural Science Foundation of China (Grant no. 51038006) and the Special Research Fund for the Doctoral Program of Higher Education (Grant no. 20110002130002).

\section{References}

[1] Y. Q. Wang, Z. X. Wang, F. X. Yin et al., "Experimental study and finite element analysis on the local buckling behavior of aluminum alloy beams under concentrated loads," Thin-Walled Structures, vol. 105, pp. 44-56, 2016.

[2] H. X. Yuan, Y. Q. Wang, T. Chang, X. X. Du, Y. D. Bu, and Y. J. Shi, "Local buckling and postbuckling strength of extruded aluminium alloy stub columns with slender I-sections," ThinWalled Structures, vol. 90, pp. 140-149, 2015.

[3] G. O. Adeoti, F. Fan, Y. Wang, and X. Zhai, "Stability of 6082T6 aluminium alloy columns with $\mathrm{H}$-section and rectangular hollow sections," Thin-Walled Structures, vol. 89, pp. 1-16, 2015.

[4] W. Yuanqing, L. Xiaochen, S. Yongjiu et al., "Finite element analysis on mechanical performance of TEMCOR joints in aluminum alloy shell structures," Journal of Tianjin University (Science and Technology), vol. 7, pp. 1-8, 2015.

[5] G. D. Matteis, A. Mandara, and F. M. Mazzolani, "T-stub aluminum joints: influence of behavioural parameters," Computers and Structures, vol. 78, no. 1-3, pp. 311-327, 2000.

[6] B. Atzori and P. Lazzarin, "Notch sensitivity and defect sensitivity under fatigue loading: two sides of the same medal," International Journal of Fracture, vol. 107, no. 1, pp. 1-8, 2000.

[7] A. De-Andrés, J. L. Pérez, and M. Ortiz, "Elastoplastic finite element analysis of three-dimensional fatigue crack growth in aluminum shafts subjected to axial loading," International Journal of Solids \& Structures, vol. 36, no. 15, pp. 2231-2258, 1999.

[8] Y. Hiyama, K. Ishikawa, S. Kato, and S. Okubo, "Experiments and analysis of the post-buckling behaviors of aluminum alloy double layer space grids applying ball joints," Structural Engineering and Mechanics, vol. 9, no. 3, pp. 289-304, 2000. 
[9] J. Bin, Z. Qilin, L. Xiaoqun et al., "Study on hysteretic behavior of aluminum alloy energy dissipation braces," Journal of Building Structures, vol. 36, no. 8, pp. 49-57, 2015.

[10] W. Ramberg and W. R. Osgood, "Description of stress-strain curves by three parameters," Tech. Rep. 902, Archive and Image Library, 1943.

[11] O. Steinhardt, "Aluminum construction in the field of civil engineering," Aluminium, vol. 47, no. 2, pp. 131-139, 1971.

[12] F. M. Mazzolani, Proposal to Classify the Aluminum Alloy on the Basis of Mechanical Behavior, vol. 16 of ECCS Committee, 1974.

[13] J. L. Chaboche, "Time-independent constitutive theories for cyclic plasticity," International Journal of Plasticity, vol. 2, no. 2, pp. 149-188, 1986.

[14] W. Zhang, X.-K. Xiao, and G. Wei, "Constitutive relation and fracture model of 7A04 aluminum alloy," Explosion and Shock Waves, vol. 31, no. 1, pp. 81-87, 2011.

[15] H. Krawinkler and M. Zohrei, "Cumulative damage in steel structures subjected to earthquake ground motions," Computers \& Structures, vol. 16, no. 1-4, pp. 531-541, 1983.

[16] H. Hibbitt, B. Karlsson, and P. Sorensen, ABAQUS Analysis User's Manual Version 6.10, Dassault Systemes Simulia Corp, Providence, RI, USA, 2011.

[17] K. H. Nip, L. Gardner, C. M. Davies, and A. Y. Elghazouli, "Extremely low cycle fatigue tests on structural carbon steel and stainless steel," Journal of Constructional Steel Research, vol. 66, no. 1, pp. 96-110, 2010.

[18] Y. Shi, M. Wang, and Y. Wang, "Experimental and constitutive model study of structural steel under cyclic loading," Journal of Constructional Steel Research, vol. 67, no. 8, pp. 1185-1197, 2011.

[19] Y. Q. Wang, T. Chang, Y. J. Shi, H. X. Yuan, L. Yang, and D. F. Liao, "Experimental study on the constitutive relation of austenitic stainless steel S31608 under monotonic and cyclic loading," Thin-Walled Structures, vol. 83, pp. 19-27, 2014. 

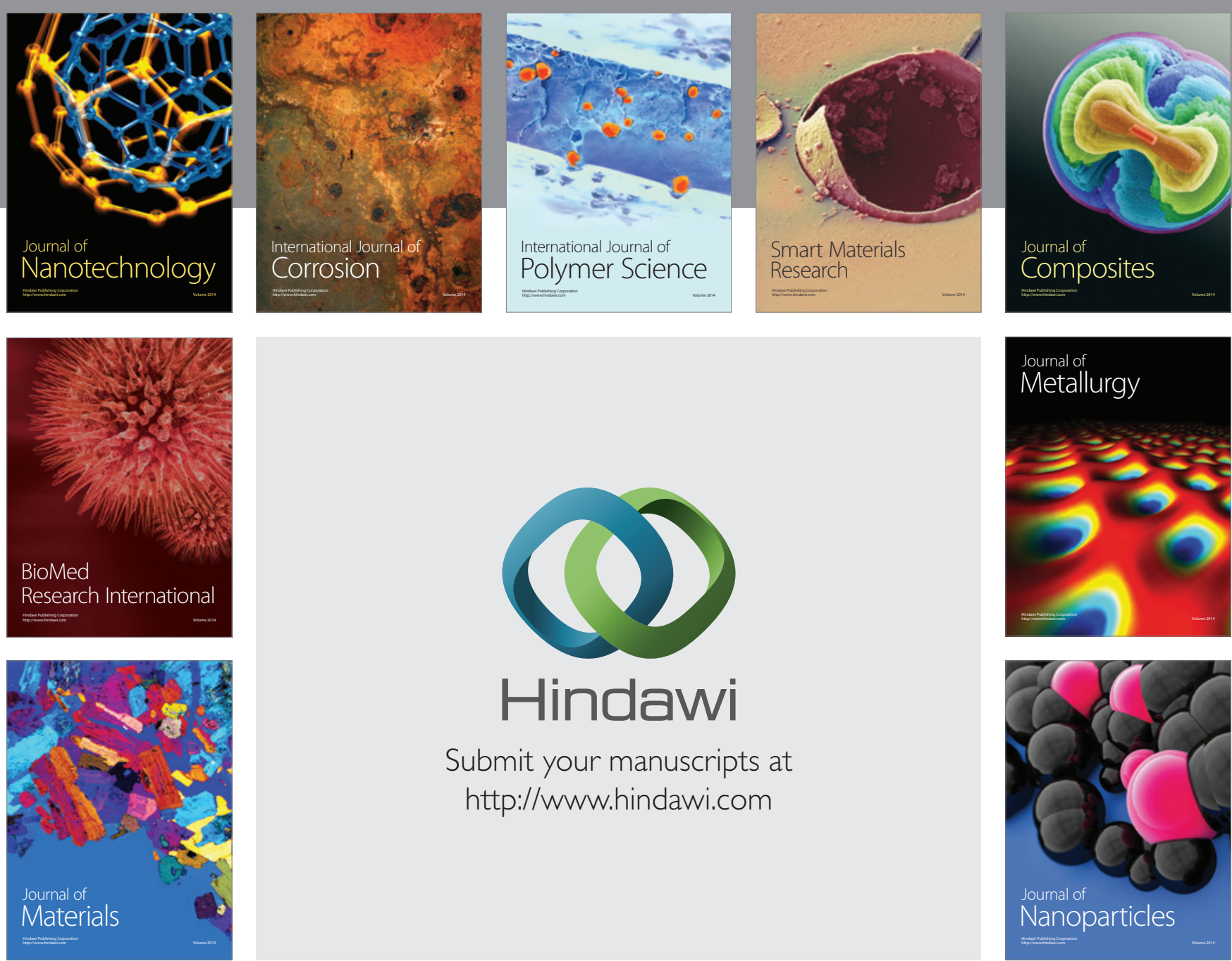

\section{Hindawi}

Submit your manuscripts at

http://www.hindawi.com

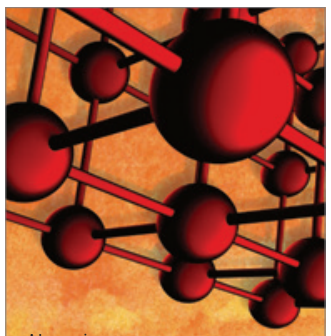

Materials Science and Engineering
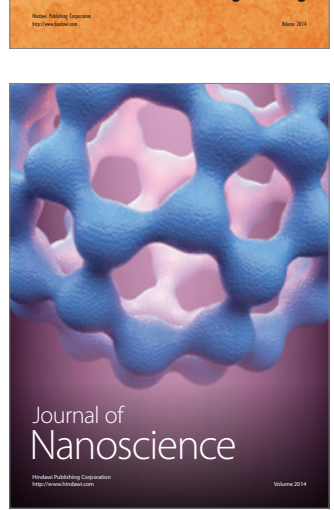
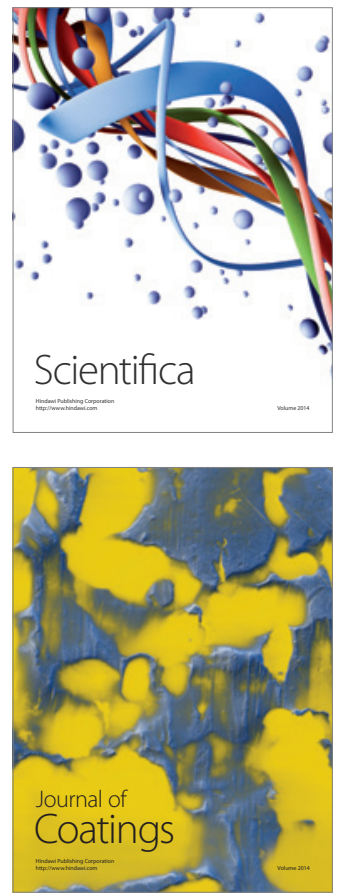
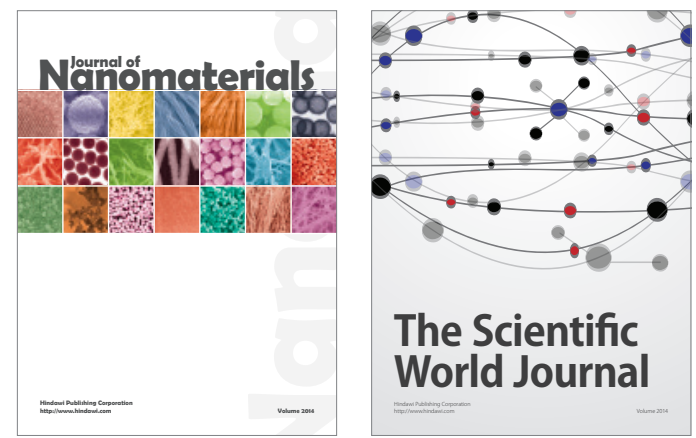

The Scientific World Journal
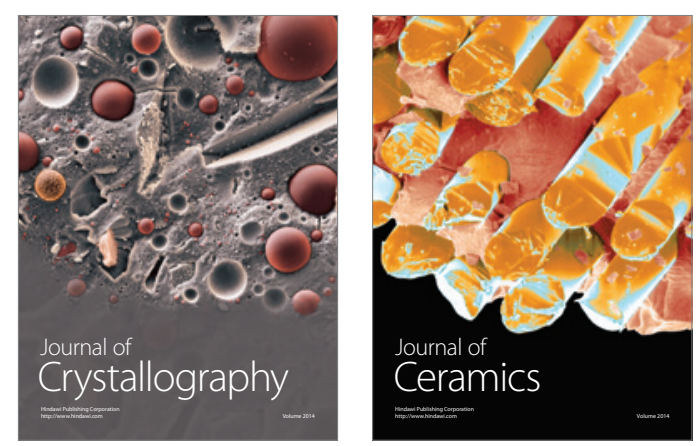
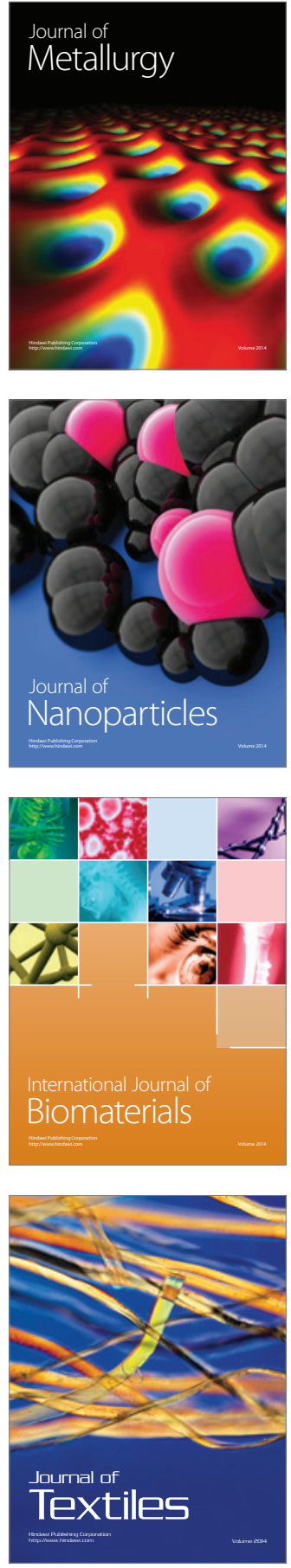